University of Wollongong

Research Online

Faculty of Engineering and Information

Faculty of Engineering and Information

Sciences - Papers: Part A

Sciences

January 2016

\title{
Modelling geogrid-reinforced railway ballast using the discrete element method
}

Ngoc Trung Ngo

University of Wollongong, trung@uow.edu.au

Buddhima Indraratna

University of Wollongong, indra@uow.edu.au

Cholachat Rujikiatkamjorn

University of Wollongong, cholacha@uow.edu.au

Follow this and additional works at: https://ro.uow.edu.au/eispapers

Research Online is the open access institutional repository for the University of Wollongong. For further information contact the UOW Library: research-pubs@uow.edu.au 


\title{
Modelling geogrid-reinforced railway ballast using the discrete element method
}

\begin{abstract}
Rail ballast is an unbounded granular material that spreads laterally when subjected to train loading. Railroads can be reinforced by geogrids to reduce lateral movement and to optimize track performance. This paper presents a study of the behaviour of geogrid-reinforced ballast subjected to monotonic and cyclic loading using a large-scale direct shear box and a novel Track Process Simulation Apparatus (TPSA). The shear stress-strain response of fresh and fouled ballast reinforced by geogrid was investigated using large-scale direct shear tests subjected to normal stresses from $15 \mathrm{kPa}$ to $75 \mathrm{kPa}$, where the levels of fouling varied from $20 \%$ to $95 \%$ Void Contamination Index (VCI). Cyclic tests for fresh and fouled ballast were conducted using the TPSA to realistically simulate real track conditions. The experimental results showed that a geogrid provides extra internal confinement and interlocks the aggreagtes in its apertures, hence reduces ballast deformation. The discrete element method (DEM) was used to model geogrid-reinforced fresh and fouled ballast subjected to monotonic and cyclic loading. Irregularly-shaped particles and geogird were simulated by clumping spherical balls together, while the coal fines were simulated by adding $1.5 \mathrm{~mm}$ diameter spheres into the pore spaces of ballast. The predicted stress-displacement responses obtained from the DEM were in good agreement with those measured in the laboratory, where the peak shear stress of fouled ballast decreased and the dilation of fouled ballast increased with an increasing level of fouling. The contact force distributions and the orientations of normal and shear force were analyzed to provide more insight into the behaviour of ballast subjected to shearing.
\end{abstract}

\section{Keywords}

element, discrete, ballast, railway, method, reinforced, modelling, geogrid

\section{Publication Details}

Ngo, N., Indraratna, B. \& Rujikiatkamjorn, C. (2016). Modelling geogrid-reinforced railway ballast using the discrete element method. Transportation Geotechnics, 8 86-102. 


\section{Accepted Manuscript}

Modelling geogrid-reinforced railway ballast using the discrete element method

Ngoc Trung Ngo, Buddhima Indraratna, Cholachat Rujikiatkamjorn

PII:

S2214-3912(16)30008-3

DOI:

http://dx.doi.org/10.1016/j.trgeo.2016.04.005

Reference:

TRGEO 81

To appear in:

Transportation Geotechnics

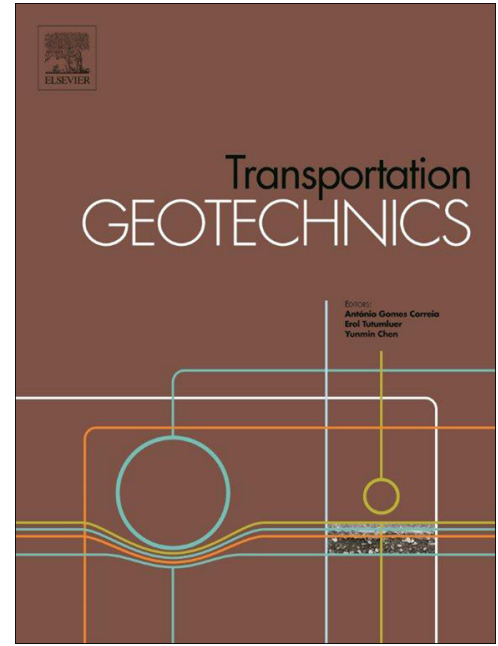

Received Date: $\quad 14$ May 2015

Revised Date: $\quad 25$ April 2016

Accepted Date: $\quad 25$ April 2016

Please cite this article as: N.T. Ngo, B. Indraratna, C. Rujikiatkamjorn, Modelling geogrid-reinforced railway ballast using the discrete element method, Transportation Geotechnics (2016), doi: http://dx.doi.org/10.1016/j.trgeo. 2016.04.005

This is a PDF file of an unedited manuscript that has been accepted for publication. As a service to our customers we are providing this early version of the manuscript. The manuscript will undergo copyediting, typesetting, and review of the resulting proof before it is published in its final form. Please note that during the production process errors may be discovered which could affect the content, and all legal disclaimers that apply to the journal pertain. 


\section{Modelling geogrid-reinforced railway ballast using the discrete element method}

Ngoc Trung Ngo, PhD, MEng, BEng

Lecturer, Centre for Geomechanics and Railway Engineering, Faculty of Engineering and Information sciences, University of Wollongong, Wollongong City, NSW 2522, Australia; ARC

Centre for Excellence for Geotechnical Science and Engineering, Australia Faculty of Engineering, Australia

Buddhima Indraratna, BSc (Eng), MSc (Lond.), DIC, PhD (Alberta), FIEAust.,FTSE, FASCE Research Director, Professor of Civil Engineering, Centre for Geomechanics and Railway Engineering, Faculty of Engineering and Information sciences, University of Wollongong, Wollongong, NSW 2522, Australia. ARC Centre for Excellence for Geotechnical Science and Engineering, Australia

Cholachat Rujikiatkamjorn, $\mathrm{PhD}$, MEng, BEng

Associate Professor, Centre for Geomechanics and Railway Engineering, Faculty of Engineering and Information sciences, University of Wollongong, Wollongong City, NSW 2522, Australia;

ARC Centre for Excellence for Geotechnical Science and Engineering, Australia Faculty of Engineering, Australia

Technical paper submitted to: TRANSPORTATION GEOTECHNICS JOURNAL

Author for correspondence:

Distinguished Professor. Buddhima Indraratna

Faculty of Engineering and Information sciences

University of Wollongong

Wollongong, NSW 2522

Australia.

Ph: +61242213046

Fax: +61242213238

Email: indra@uow.edu.au 


\section{Modelling geogrid-reinforced railway ballast using the discrete element method}

Ngoc Trung Ngo ${ }^{1}$, Buddhima Indraratna ${ }^{2}$, and Cholachat Rujikiatkamjorn ${ }^{3}$

${ }^{1}$ Lecturer, Centre for Geomechanics and Railway Engineering, Faculty of Engineering and Information Sciences, ARC Centre of Excellence for Geotechnical Science and Engineering University of Wollongong, Wollongong, NSW 2522, Australia. Email: trung@uow.edu.au, Ph: +61 2 4221 4892 Fax: +61242213238

${ }^{2}$ Research Director, Professor of Civil Engineering, Centre for Geomechanics and Railway Engineering, Faculty of Engineering and Information Sciences, ARC Centre of Excellence for Geotechnical Science and Engineering, University of Wollongong, Wollongong, NSW 2522, Australia. Email: indra@uow.edu.au, Ph: +61242213046 Fax: +61242213238

${ }^{3}$ Associate Professor, Centre for Geomechanics and Railway Engineering, Faculty of Engineering and Information Sciences, ARC Centre of Excellence for Geotechnical Science and Engineering, University of Wollongong, Wollongong, NSW 2522, Australia. Email:

cholacha@uow.edu.au, Ph: +61242215852 Fax: +61242213238

\section{ABSTRACT}

Rail ballast is an unbounded granular material that spreads laterally when subjected to train loading. Railroads can be reinforced by geogrids to reduce lateral movement and to optimize track performance. This paper presents a study of the behaviour of geogrid-reinforced ballast subjected to monotonic and cyclic loading using a large-scale direct shear box and a novel Track Process Simulation Apparatus (TPSA). The shear stress-strain response of fresh and fouled ballast reinforced by geogrid was investigated using large-scale direct shear tests subjected to normal stresses from $15 \mathrm{kPa}$ to $75 \mathrm{kPa}$, where the levels of fouling varied from $20 \%$ to $95 \%$ Void Contamination Index (VCI). Cyclic tests for fresh and fouled ballast were conducted using the TPSA to realistically simulate real track conditions. The experimental results showed that a geogrid provides extra internal confinement and interlocks the aggreagtes in its apertures, hence reduces ballast deformation. The discrete element method (DEM) was used to model geogridreinforced fresh and fouled ballast subjected to monotonic and cyclic loading. Irregularly-shaped particles and geogird were simulated by clumping spherical balls together, while the coal fines were simulated by adding $1.5 \mathrm{~mm}$ diameter spheres into the pore spaces of ballast. The predicted stress-displacement responses obtained from the DEM were in good agreement with those measured in the laboratory, where the peak shear stress of fouled ballast decreased and the dilation of fouled ballast increased with an increasing level of fouling. The contact force distributions and 
the orientations of normal and shear force were analyzed to provide more insight into the behaviour of ballast subjected to shearing.

\section{Introduction}

Railways provide an efficient and economic mode of transport in many countries and ballast is an essential component of rail tracks used as a load bearing platform and for maintaining track alignment (Selig and Waters 1994). It usually consists of medium to coarse aggregates whose main functions are to: (i) distribute the train load to the layer of sub-ballast at a reduced level of stress; (ii) provide lateral confinement to the track, and (iii) provide a free draining condition. Upon repeated train loads ballast deteriorates and spreads laterally causing track instability (Indraratna et al. 2011a; Ngo et al. 2014). Moreover, due to progressive degradation and the infiltration of fine particles and mud-pumping from the lower subgrade, ballast becomes fouled, which adversely affects the strength and deformation of ballasted tracks (Budiono et al. 2004; Lackenby et al. 2007; Tutumluer et al. 2008; Fortunato et al. 2010; Indraratna et al. 2013). Given the typical Australian coal freight tracks, Feldman and Nissen (2002) reported that dry coal fines are responsible for $70-95 \%$ of the fouling materials in rail tracks.

Geogrids have been widely used in the substructure of rail tracks to reinforce the ballast and to increase the duration of track serviceability (Raymond 2002; McDowell and Stickley 2006; Brown et al. 2007; Fernandes et al. 2008; Kwon and Penman 2009; Indraratna et al. 2011a). It has been reported that due to the mechanical interlock with aggregates, geogrids can decrease lateral spreading and the degradation of ballast (Bathurst and Raymond 1987; Brown et al. 2006; Indraratna et al. 2013; Biabani et al. 2016a). Despite these benefits, current literature on the interface behaviour of geogrid-ballast subjected to monotonic and cyclic loadings is still limited both in experimental study and numerical simulation, particularly when ballast becomes fouled (Tutumluer et al. 2011; Chen et al. 2012; Ngo et al. 2015). This paper presents the major results of tests conducted in the laboratory at the University of Wollongong, where static and cyclic testing of ballast (latite basalt) were conducted using large-scale apparatus. Large-scale direct shear tests were carried out for fresh and coal-fouled ballast with and without the inclusion of geogrid to study the interface behaviour of ballast and geogrid. To examine the cyclic response of geogridreinforced fouled ballast, a novel Track Process Simulation Apparatus (TPSA) was also used for coal-fouled ballast under various levels of fouling. A numerical simulation using the discrete 
element method (DEM) was carried out to model the interface behaviour of geogrid reinforced fouled ballast subjected to monotonic and cyclic loading.

\section{Experimental study}

\subsection{Large-scale direct shear test}

The large-scale direct shear test apparatus used in this study consisted of a $300 \mathrm{~mm} \times 300 \mathrm{~mm}$ plane area and a $200 \mathrm{~mm}$ high steel box that was divided horizontally into two equal halves. A schematic diagram of the large-scale direct shear test is shown in Figure 1. A series of tests were conducted for fouled ballast with and without geogrid, subjected to relatively low normal stresses ranging from $15 \mathrm{kPa}$ to $75 \mathrm{kPa}$, to simulate typical track conditions (Lackenby et al. 2007). Coal fines were used as fouling material and the Void Contamination Index (VCI) proposed earlier by (Indraratna et al. 2010a) was used to quantify the levels of ballast fouling, as given by:

$V C I=\frac{1+e_{f}}{e_{b}} \times \frac{G_{s b}}{G_{s f}} \times \frac{M_{f}}{M_{b}} \times 100$

where $e_{f}=$ the void ratio of fouling material, $e_{b}=$ the void ratio of fresh ballast, $G_{s b}=$ the specific gravity of ballast, $G_{s f}=$ the specific gravity of fouling material, $M_{f}=$ the dry mass of fouling material, and $M_{b}=$ the dry mass of fresh ballast.

A series of large-scale direct shear tests for fresh and coal-fouled ballast reinforced by the geogrid were carried out and the results discussed elsewhere by Indraratna et al. (2011b), while some of these data were used in this study to calibrate DEM models. The test was sheared at a horizontal displacement of $\Delta h=37 \mathrm{~mm}$ (e.g. the maximum movement allowed by the direct shear test apparatus). Figure 2 shows the stress-displacement and dilation response of fouled ballast with and without geogrid reinforcement where the level of coal fines varied from VCI=20\% to VCI=95\%. Here the peak shear stresses of fouled ballast increased with an increase in normal stress and then decreased with an increased level of fouling. Strain softening and volumetric dilation behaviour were obtained for all tests, where the higher normal stresses $\left(\sigma_{n}\right)$, the greater peak stress, and smaller dilations were observed. Tutumluer et al. (2008) also presented similar shear stress-strain softening behaviour of railway ballast that they had measured experimentally. 


\subsection{Track Process Simulation Apparatus (TPSA)}

Cyclic tests for coal-fouled ballast were conducted using the TPSA (800 mm long, $600 \mathrm{~mm}$ wide and $600 \mathrm{~mm}$ high), fabricated to simulate realistic track conditions (Figure 3). The schematic plane view and cross-section of the TPSA is shown in Figure 4. The ballast and sub-ballast used in this study was collected from Bombo quarry near Wollongong, Australia, then cleaned and sieved according to AS 2758.7 (Australia Standards 1996). Ballast aggregates are obtained by quarrying the parent rock, latite basalt of volcanic origin. In the state of NSW, this is one of the most commonly used ballast for both heavy haul and commuter tracks. The subgrade was well-graded gravelly sand compacted at $7 \%$ moisture content to a unit weight of $18.5 \mathrm{kN} / \mathrm{m}^{3}$. The particle size distributions of the materials used in this study are shown in Figure 5. The sub-ballast was placed into the apparatus in $50 \mathrm{~mm}$ thick layers and then compacted to a field unit weight of approximately $18.5 \mathrm{kN} / \mathrm{m}^{3}$. Ballast aggregates were then placed on the layer of sub-ballast and compacted to obtain a field unit weight of $15.3 \mathrm{kN} / \mathrm{m}^{3}$. Two lateral pressures $\left(\sigma_{2}=10 \mathrm{kPa}\right.$ and $\sigma_{3}=7 \mathrm{kPa}$ ) that corresponded to the confining pressures provided by crib and shoulder ballast in the field were applied to the vertical walls (Figure 3); they are based on actual track measurements (Indraratna et al. 2013; Biabani et al. 2016b). An initial vertical pressure of $45 \mathrm{kPa}$ was then applied to stabilise the sleeper and ballast. To simulate a 30 tonne axle freight train travelling at approximately $80 \mathrm{~km} / \mathrm{h}$, a cyclic load was applied through a servo hydraulic actuator with a maximum pressure of $420 \mathrm{kPa}$ and frequency of $15 \mathrm{~Hz}$. During the tests, vertical and lateral movements were recorded automatically using a system of steel pegs and electronic potentiometers. All tests were conducted at a frequency of $15 \mathrm{~Hz}$ up to 500,000 load cycles. The results and analysis of these tests were presented elsewhere by Indraratna et al. (2013). They highlighted that geogrid-reinforced ballast exhibits less deformation when compared to an unreinforced assembly at any given level of fouling. As expected, an increasing level of fouling results in increased ballast settlement, as shown in Figure 6. All the specimens exhibited an initial rapid settlement up to 100,000 cycles, followed by a gradually increasing settlement within 300,000 cycles, and then remained relatively stable to the end (500,000 cycles). This clearly shows that ballast aggregates were subjected to a significant rearrangement and densification during initial load cycles, but when the ballast attained a threshold compression, any subsequent loading would resist further settlement and promote dilation, unless particle breakage occurs. 


\section{Discrete Element Modelling}

The discrete element method (DEM) introduced by Cundall and Strack (1979) has been widely used to study shear behaviour of fresh and fouled ballast (Lim and Mcdowell 2005; LoboGuerrero and Vallejo 2006; Lu and Mcdowell 2008; Huang and Tutumluer 2011; Tutumluer et al. 2011; Chen et al. 2012; Indraratna et al. 2014; Ngo et al. 2014). The force-displacement law derives the contact force acting on two entities in contact with the relative displacement between them. If particle B with radius $R^{[B]}$ is in contact with particle A with radius of $R^{[A]}$, or in contact with a wall (Figure 7), the particle penetration depth $\left(U^{n}\right)$ is defined as:

$U^{n}=\left\{\begin{array}{lr}R^{[A]}+R^{[B]}-d, & (\text { particle }- \text { particle }) \\ R^{[B]}-d, & (\text { particle }- \text { wall })\end{array}\right.$

where, $d$ is the distance between the particle to particle centres, given as:

$d=\left|x_{i}^{[B]}-x_{i}^{[A]}\right|=\sqrt{\left(x_{i}^{[B]}-x_{i}^{[A]}\right)\left(x_{i}^{[B]}-x_{i}^{[A]}\right)}$

The location of the contact point is given by:

$x_{i}^{[C]}=\left\{\begin{array}{lr}x_{i}^{[A]}+\left(R^{[A]}-\frac{1}{2} U^{n}\right) n_{i}, & (\text { particle }- \text { particle }) \\ x_{i}^{[B]}+\left(R^{[B]}-\frac{1}{2} U^{n}\right) n_{i}, & (\text { particle }- \text { wall })\end{array}\right.$

where, $n_{i}$ is the unit vector, and is determined by:

$n_{i}=\frac{x_{i}^{[B]}-x_{i}^{[A]}}{d}$

The force vector $\overrightarrow{\boldsymbol{F}}$ that represents the interaction between the two particles is resolved into normal $\left(\overrightarrow{\boldsymbol{F}}_{N}\right)$ and shear component $\left(\overrightarrow{\boldsymbol{F}}_{T}\right)$ with respect to the contact plane:

$\overrightarrow{\boldsymbol{F}}_{N}=K_{N} \cdot U^{n}$

$\delta \overrightarrow{\boldsymbol{F}}_{T}=-K_{T} \cdot \delta U^{S}$

where, $K_{N}$ and $K_{T}$ are the normal and shear stiffnesses at the contact; $\delta U^{S}$ is the incremental shear displacement, and $\delta \overrightarrow{\boldsymbol{F}}_{T}$ is the incremental shear force. 
The normal contact stiffness for the linear contact model used in this study was computed as:

$K_{N}=\frac{k_{n}^{[A]} k_{n}^{[B]}}{k_{n}^{[A]}+k_{n}^{[B]}}$

and the contact shear stiffness is given by:

$K_{T}=\frac{k_{s}^{[A]} k_{s}^{[B]}}{k_{s}^{[A]}+k_{s}^{[B]}}$

where, $k_{n}^{[A]}, k_{n}^{[B]}, k_{s}^{[A]}, k_{s}^{[B]}$ are the normal stiffness and shear stiffness of particle A and B, respectively.

The new shear contact force is determined by summing the old shear force existing at the start of the time-step with the shear elastic force increment

$\overrightarrow{\boldsymbol{F}}_{T} \leftarrow \overrightarrow{\boldsymbol{F}}_{T}+\delta \overrightarrow{\boldsymbol{F}}_{T} \leq \mu \overrightarrow{\boldsymbol{F}}_{N}$

where, $\mu$ is the coefficient of friction.

\subsection{Modeling the ballast, coal fouling, and geogrid in DEM}

The irregular shaped grains were modelled by connecting and overlapping together many spheres of different sizes and positions (ITASCA 2012). The commercial software package, Particle Flow Code in Three Dimensions (PFC3D) version 4.0 produced by ITASCA (2012) has been employed in this study. A library of nine varying shaped ballast was then developed to simulate ballast aggregates, as shown in Figure 8a. This method has been widely used by Lim and McDowell (2005); Lu and McDowell (2008); Ferellec and McDowell (2010); Thakur et al. (2010). A large scale shear box $(300 \mathrm{~mm}$ long $\times 300 \mathrm{~mm}$ wide $\times 200 \mathrm{~mm}$ high) was simulated in DEM with rigid walls to simulate fresh and fouled ballast ( $\mathrm{VCI}=40 \%)$, as shown in Figures $8 \mathrm{c}-\mathrm{d}$. These simulated irregular particles were then placed in the shear box at random orientations and compacted to a void ratio of 0.82 (i.e. porosity of $45 \%$ ) to resemble experiment conditions.

Fouling is caused by fine particles that accumulate within ballast voids. In this study, fouled ballast was simulated in DEM by adding a certain amount of fine particles into the voids to represent different values of VCI. Fouled ballast with 40\%VCI was modelled by injecting 145,665 $1.5 \mathrm{~mm}$ diameter spheres into the voids of fresh ballast (Figure $8 \mathrm{~d}$ ). Geogrids with $40 \mathrm{~mm} \times 40 \mathrm{~mm}$ 
apertures, similar to those tested in the laboratory, were modelled by bonding small spherical balls together (i.e., balls with a $2 \mathrm{~mm}$ radius at the ribs and a $4 \mathrm{~mm}$ radius at the junctions), as shown in Figure $8 \mathrm{~b}$. These balls were connected by parallel bonds that represent the geogrid's tensile strength. Based on the test results obtained from large-scale direct shear testing reported by Indraratna et al. (2011b), a set of micromechanical parameters adopted for DEM simulation of ballast, geogrid, and coal fines are given in Table 1. A linear contact model, following previous studies, was used for the numerical simulations (e.g. Thakur et al. 2010; Indraratna et al. 2010b; McDowel et al. 2006).

\section{Results and discussion}

\subsection{Shear stress-strain and volumetric change analysis}

A series of large scale direct shear tests were conducted in the laboratory and DEM simulation to examine the shear stress-displacement of fresh and fouled ballast reinforced by geogrid. While the major experimental results were presented and discussed elsewhere by Indraratna et al. (2011b), some of their results are presented herein to compare with the DEM model. The shear box consists of an upper box that was restrained from any lateral movement, while the lower box was forced to shear horizontally at a rate of at $2.5 \mathrm{~mm} / \mathrm{min}$. Figures $9 \mathrm{a}, 9 \mathrm{~b}$ present comparisons of the shear stress-displacement and volumetric dilation of the geogrid-reinforced fresh and fouled ballast measured in the laboratory, and those obtained from the DEM simulations, while Figures 9c, 9d show shear stress-displacement and volumetric dilation of unreinforced-fresh and fouled ballast (VCI $=40 \%$ ), respectively. The predicted results at any given normal stress agree well with the experimental data, indicating that the proposed DEM model could capture the shear behaviour of fresh and fouled ballast. As expected, fresh ballast exhibited higher shear stress and lower volumetric dilation than the $40 \%$ VCI-fouled ballast. The strain softening behaviour of ballast follows a similar trend with other rockfill aggregates of comparable sizes (e.g. Marsal, 1973; Charles and Watts, 1980), and as expected, volumetric dilation was also observed in all simulations, whereby the greater the normal stress the higher the peak stress and the smaller the dilation. The DEM analysis showed a slightly higher dilation than the experimental data for $\sigma_{n}=27 \mathrm{kPa}$ compared to the higher normal stress levels in a shear displacement range of 10-25 $\mathrm{mm}$ (i.e. $4-8 \%$ shear strain). This difference is basically associated with some particle breakage that was not captured in the DEM simulation. Lackenby et al. (2007) reported that particle 
degradation could increase ballast compression. The Ballast Breakage Index (BBI) after the tests of fresh and fouled ballast $(\mathrm{VCI}=40 \%$ ) were measured at 0.123 and 0.083 , respectively. The laboratory results also showed a sudden drop in shear stress at $4-8 \%$ shear strain, before picking up the load again, which further supports the initiation of particle degradation at this level of shear strain.

Strains that developed in the geogrids could not be measured in the laboratory due to the complexity of installing strain gauges to the geogrid, and the difficulty of preventing them from being damaged by compaction and the sharp edges of ballast aggregates. By taking advantage of the numerical analysis, the strains developed across the geogrid in a horizontal shearing direction were captured in the simulations. Figure 10a-b shows the contours of strain that developed across the geogrid at the end of the shear test $(\Delta h=37 \mathrm{~mm})$ for fresh ballast and fouled ballast (VCI=40\%); they indicate that the strains developed non-uniformly across the geogrid, and the magnitude of strain depends on the interlock between the geogrid and ballast particles. The geogrids placed in the $40 \%$ VCI fouled ballast assembly experienced a slightly lower maximum strain than those in fresh ballast (i.e. $1.00 \%$ strain for fouled ballast compared to $1.405 \%$ strain in fresh ballast). This would be associated with the decreased interlocking effect by the geogrid and ballast particles due to coal fines clogging the interface of geogrid-ballast.

\subsection{Load-deformation response of ballast subjected to cyclic load}

A total of 10 cyclic tests using the TPSA for coal-fouled ballast with and without geogrid, and VCI were carried out. The particle size distributions of materials used for the tests were shown earlier in Figure 5. The lateral displacement and vertical settlement of the ballast were measured during the test using potentiometers and settlement plates, as shown in Figure 3-4. The lateral displacement and settlement of coal-fouled ballast with and without geogrid are presented in Figure 11. It was observed that geogrid-reinforced ballast deformed less than the unreinforced ballast assembly for any given VCI. All the samples experienced an initial rapid settlement up to 100,000 cycles, followed by gradually increasing settlement within 300,000 cycles, and then remained relatively stable thereafter; probably because the geogrid created a strong mechanical interlock with the surrounding ballast grains and prevented them from free movement. This interlocking effect enabled the geogrid to act like a non-displacement boundary which decreased ballast deformation. This agreed with previous studies conducted by (McDowell et al. 2006) where the discrete element method (DEM) was used to examine the interaction between geogrid 
and ballast. They reported that the geogrid formed a stiffened zone inside the ballast assembly that acted like reinforcement. An increased level of fouling resulted in much higher settlement, indeed as the fouling increases the coal fines acted like a lubricant and helped the particles to slide and/or roll over each other, which in turn, increased deformation. However, the ability of geogrid to decrease ballast deformation also decreased as the VCI increased because as coal fines accumulated in the apertures of the geogrids it reduced their effective size (Indraratna et al. 2011b).

DEM simulation was also used to examine the cyclic behaviour of fresh and fouled ballast by simulating the TPSA in a plane strain condition. The ballast aggregates simulated in two dimensions that were developed by Indraratna et al. (2010b) were used in the analysis where clusters of bonded circular particles were used to model irregular-shaped ballast aggregates and the degradation of bonds within a cluster was possibly considered to represent ballast breakage. It is noted that the shape of particles directly influences how coarse angular aggregates interact, which reflects its specific stress-strain and degradation characteristics. It is noteworthy that if a 3D DEM model is conducted for cyclic loading then the number of cycles and the rate of convergence are further affected compared to a 2D cyclic analysis. The difference between $3 \mathrm{D}$ analysis and 2D analyses in terms of particle shape effect can affect both the shear strength and the corresponding volumetric change of ballast assemblies, because angular particles in 3D represent increased interparticulate interaction or interlock compared to the $2 \mathrm{D}$ projection of particle angularity. Therefore, given the same set of micromechanical properties of ballast assembly, the three-dimensional analysis would exhibit a higher shear strength and greater volumetric dilation (i.e. higher friction angle gives a higher dilation angle) compared to those obtained from two-dimensional analysis. Due to a limitation of the commercial software package, PFC3D- Particle Flow Code that the Authors used to perform a 3D analysis, where "clump logic" was used to represent the actual particle angularity. These clumps behave like rigid bodies (i.e. internal contacts are ignored, hence no particle breakage), whereas in 2D analysis, the Authors have used "bonding contacts" which allow particle breakage to be considered. So this $2 \mathrm{D}$ analysis is approximate simplified approach where particle degradation under cyclic loads can still be captured (albeit not perfectly) within a reasonable computational timeframe.

The DEM models used to simulate fresh and fouled ballast in the TPSA are illustrated in Figure 12. A small uniformly distributed load of $2.5 \mathrm{kPa}$ was applied on the ballast surface to simulate the slight confining effect induced by ballast cribs. Subroutines were developed by the Authors to 
apply a stress-controlled cyclic load to the models, similar to the boundary loading condition tested in the laboratory. Cyclic tests for fresh and fouled ballast at $V C I=10 \%, 20 \%, 40 \%$ and $70 \%$ were simulated to a number of load cycles, $N=4000$, where most of the ballast deformation and degradation took place, as observed in the laboratory. Lateral displacement and vertical settlement of the fresh and fouled ballast assembly corresponding with load cycles were captured during these simulations. Figure 13 presents the comparisons of predicted lateral displacements and settlements with those measured in the laboratory, and they indicated that the DEM simulation capably captured the deformation of fresh and fouled ballast subjected to cyclic loading at any given VCI. The DEM simulations confirmed that the degree of fouling affected ballast deformation with increase in VCI that resulted in an increase in lateral displacement that led to increased settlement. Moreover, the volumetric dilation predicted by DEM was somewhat higher than the dilation actually measured because the inevitable variation in particle angularity between the DEM model and actual ballast, as well as particle degradation, was not considered in the numerical analysis.

It is noted that for studying the behaviour of rail track a higher number of cycles should normally be considered (i.e. laboratory or finite element analysis) to fully capture the deformation and degradation of granular assemblies over a longer period of cyclic loading. However, the highest rate of particle densification and breakage of high angular corners of particles occur during the initial loading cycles, $\mathrm{N}<5000$ (Indraratna et al. 2011a). The DEM analysis was performed for 4000 cycles to insightfully capture this initial deformation of ballast aggregates in a micromechanical perspective, while recognizing the serious limitation of most discrete element software to converge at large number of cycles unlike continuum-based FEM software. The current DEM models (PFC3D) have obvious limitations due to excessive computational time required, where a large number of cycles (e.g. $\mathrm{N}=100,000)$ cannot be simulated, even with the high-end DELL super-computer used for this study

\section{Micromechanical analysis}

Load transfer in a granular assembly depends on the orientation of contacts where the applied load is transmitted to a granular assembly through an interconnected network of force chains at contact points (Oda and Iwashita 1999). When subjected to shearing, the contact forces of ballast assemblies evolve so that the number of load-carrying contacts and their orientations inevitably 
change. In this study, the second-order density distribution tensor introduced by Rothenburg (1980) was used to examine the anisotropy of contact forces of the ballast assembly at different settlements. These tensors were incorporated into the DEM models and are given as follows:

$F_{i j}=\int_{0}^{2 \pi} E(\theta) n_{i} n_{j} d \theta=\frac{1}{N_{c}} \sum_{k=1}^{N_{c}} n_{i}^{k} n_{j}^{k}$

$N_{i j}=\frac{1}{2 \pi} \int_{0}^{2 \pi} \frac{\bar{f}_{n}(\theta)}{\bar{f}_{0}(\theta)} n_{i} n_{j} d \theta=\frac{1}{N_{c}} \sum_{k=1}^{N_{c}} \frac{f_{n}^{k}}{\bar{f}_{0}} n_{i}^{k} n_{j}^{k}$

$S_{i j}=\frac{1}{2 \pi} \int_{0}^{2 \pi} \frac{\bar{f}_{s}(\theta)}{\bar{f}_{0}(\theta)} t_{i} n_{j} d \theta=\frac{1}{N_{c}} \sum_{k=1}^{N_{c}} \frac{f_{s}^{k}}{\bar{f}_{0}} t_{i}^{k} n_{j}^{k}$

where, $F_{i j}, N_{i j}$, and $S_{i j}$ are fabric, average contact normal force and average contact shear force tensors, respectively; $E(\theta), \bar{f}_{n}(\theta)$, and $\bar{f}_{S}(\theta)$ are the corresponding density distribution functions; $f_{n}^{k}$ and $f_{s}^{k}$ are contact normal force and shear force, respectively; $\boldsymbol{n}=(\cos \theta, \sin \theta)$ is unit normal vector, and $\boldsymbol{t}=(-\sin \theta, \cos \theta)$ is the vector perpendicular to $\boldsymbol{n}$; and $N_{c}$ is the total number of contacts in the assembly. $\bar{f}_{0}$ is the average contact normal force determined by:

$\bar{f}_{0}=\frac{1}{2 \pi} \int_{0}^{2 \pi} \bar{f}_{n}(\theta) d \theta=\frac{1}{N_{c}} \sum_{k=1}^{N_{c}} f_{n}^{k}$

The force-fabric is characterised by the distribution of inter-particle contact orientations that can be described by the following Fourier series approximations proposed by Rothenburg and Bathurst (1989), as given below:

$E(\theta)=\frac{1}{2 \pi}\left[1+\operatorname{acos} 2\left(\theta-\theta_{a}\right)\right]$

$\bar{f}_{n}(\theta)=\bar{f}_{0}\left[1+a_{n} \cos 2\left(\theta-\theta_{n}\right)\right]$

$\bar{f}_{s}(\theta)=\bar{f}_{0}\left[-a_{s} \cos 2\left(\theta-\theta_{s}\right)\right]$

where, $a, a_{n}$, and $a_{s}$ are the coefficients of contact normal, contact normal force and contact shear force anisotropies, respectively; $\theta_{a}, \theta_{n}$, and $\theta_{s}$ are the corresponding major principal directions of anisotropies, respectively. 


\subsection{Contact force distributions}

The DEM models of the direct shear test in the current analysis were also able to capture contact force distributions of particles during shearing. Figure 14 shows the distributions of contact force chains of fresh and fouled ballast ( $\mathrm{VCI}=40 \%)$ with and without geogrid reinforcement subjected to a given normal stress of $51 \mathrm{kPa}$, at a shear displacement of $\Delta h=18 \mathrm{~mm}$. The contact forces between particles were plotted as lines whose thickness is proportional to the magnitude of the force. The thickness of the contact force lines represents the magnitude of forces while the length of each line connects the centerlines of two particles in contact. It is noteworthy that only the number of contacts and the corresponding maximum forces could be captured in the PFC3D analysis, thus the legends for the length of maximum contact force could not be applied. The fouled ballast (Figure 14b and Figure 14d) exhibited greater contact chains and reduced maximum contact force compared to those in the fresh ballast specimen (Figure 14a and Figure 14c) because fine particles accumulated in the voids between the large particles and then partially supported and transmitted forces across the specimen. Compared to the unreinforced ballast, the reinforced ballast experienced a considerable increase in the amount and magnitude of contact forces. This mobilisation of high contact forces within the geogrid-reinforced ballast assembly stemmed from the interlocking that took place between them. Maximum contact forces induced in ballast assemblies would govern the breakage where an increased intensity of inter-particle contact stresses would cause particle splitting or the breakage of angular corners.

\subsection{Polar histogram of contact forces}

The micromechanical analysis presented herein focussed on the evolution of contact force distributions of particles in the shear box at varying shear displacements. Eqs. (11)-(14) were used to capture the contact information of every particle in the DEM model while Eqs. (15)-(17) were used for the Fourier series approximation. Figure 15 shows the polar histogram of inter-particle contact force distributions for the VCI fouled ballast $(\mathrm{VCI}=40 \%)$ at different shear displacements, $\Delta h$, captured from the DEM simulation and those obtained from the Fourier approximation. Polar histograms of the contact forces were obtained by collecting the contact force information at the predefined bin angle $\Delta \theta=10^{\circ}$. When shearing commenced the inter-particle forces were almost uniformly distributed in all orientations (i.e., isotropic), as shown in Figure 15a. The normal contact force anisotropy was coaxial with vertical axes, having a principal direction of almost $\theta_{n}=4^{0}$, which is the major principal stress in the assembly. In this stage the contact shear force 
anisotropy was very small and its direction with the vertical axis was almost zero due to a very low induced shear stress. With an increase of applied shear load the contact force chains develop to resist shear and disperse the loads from the surface into the ballast. Anisotropies of average contact normal force and shear force grow and rotate vigorously as shearing progresses, and reach their values of $\theta_{n}=33^{0}, 51^{0}$ at corresponding shear displacements of $\Delta h=9 \mathrm{~mm}$, and $18 \mathrm{~mm}$, respectively. As shear displacement increases (Figure 15b, Figure 15c), the contact force anisotropies tend to align towards the horizontal axis as the number of contacts in a horizontal shearing directing increase. This provided more insight into the orientation of contacts where the applied load was transmitted to a granular assembly through an interconnected network of forces that are difficult to measure in the laboratory.

Figure 16 shows the comparisons of contact force orientation of clean ballast, geogrid-reinforced ballast and fouled ballast ( $\mathrm{VCI}=40 \%$ ) at a shear displacement of $\Delta h=9 \mathrm{~mm}$. It is seen that contact force orientation in the geogrid-reinforced ballast assembly exhibits a principal direction of $\theta_{a}=15^{\circ}$, while the clean and fouled ballast $(40 \% \mathrm{VCI})$ show contact force orientations of $\theta_{a}=24^{0}$ and $\theta_{a}=32^{0}$, respectively. The inclusion of geogrid in the fresh ballast results in increased number of contacts in the vertical direction than the unreinforced assemblies (i.e. due to the interlock between the geogrid and aggregates). The contact force orientation in the fresh ballast slightly aligns towards the vertical direction than that in the fouled ballast assembly (i.e. having a principal direction of $24^{0}$ compared to $32^{0}$ for the fouled ballast).

The micromechanical analysis presented in this paper is focusing on the evolution of contact and force orientations at varying shear displacements. This provides more insight into the orientation of contacts transmitted in ballast assemblies. It is believed that the inherent anisotropy affects the overall shear strength of ballast assemblies, while stresses within the ballast medium are composed of multiple stress chains, which can lead to localized high stress concentrations. Such high stress concentrations may lead to crushing of single particles even under relatively low applied stresses. Therefore, understanding the contact force distribution in the ballast assemblies and its evolution is most beneficial. 


\section{Practical Implications}

Based on extensive laboratory tests carried out in this study, it is found that the inclusion of geogrids provides considerable improvement on the performance of geogrid-reinforced ballast in terms of the mobilized shear strength and deformation, while the presence of fouling materials adversely decreases the performance of ballast. These influential factors need to be considered in track design when geosynthetics are utilized. In the absence of current large-scale laboratory tests on geosynthetics-reinforced ballast under monotonic and cyclic loads, the proposed DEM model in this study can be used to predict the mobilized shear strength and deformation of a composite assembly for a given degree of fouling (VCI) at a corresponding normal stress.

This DEM model offers some original insight for the practitioner to improve track design as well as to conduct a performance verification of the track considering the reduced shear strength of ballast associated with an increased level of fouling. This model is also helpful for the practitioner to perform direct shear tests and cyclic tests on granular assemblies with and without the inclusion of planar geosynthetics. 


\section{Conclusions}

This paper presents the results of large-scale laboratory tests and numerical modelling using the discrete element method (DEM) to study the performance of geogrid reinforced fouled ballast at various levels of coal fouling. The beneficial effects of geogrids on the shear strength and dilation of ballast were assessed using large scale direct shear tests. The results clearly indicated that geogrid increases the shear strength and reduces ballast dilation at a given VCI. This was justified by interlocking between the geogrid and ballast grains at the interface. Conversely, coal fines acting as lubricant coated the surfaces of ballast grains, which subsequently reduced the interparticle friction and the shearing resistance of fouled ballast assembly. A series of cyclic tests were also carried out to investigate the load-deformation response of coal-fouled ballast using a novel rail process simulation testing apparatus. The results showed that all the ballast samples experienced a considerable amount of deformation within 100,000 cycles, followed by a gradual increase in settlement up to 300,000 cycles, and then remained relatively stable.

DEM simulations were also carried out to investigate the stress-strain behaviour and corresponding volumetric change of fresh fouled ballast ( $\mathrm{VCI}=40 \%$ ). Irregular ballast grains were modelled by connecting many spherical balls together, while coal fines were simulated by placing a pre-determined amount of fine spherical balls into the ballast voids. The geogrid was modelled using bonded spherical particles with a $2 \mathrm{~mm}$ radius at the rib and a $4 \mathrm{~mm}$ radius at the junction. For a given normal stress and level of fouling the DEM simulation captured the shear stress-strain and corresponding dilation of fouled ballast. As expected, fresh ballast exhibited higher shear stress and lower volumetric dilation than the fouled ballast of $\mathrm{VCI}=40 \%$. The contact force distributions were also examined and indicated that the fouled ballast assembly experienced more uniform contact force distribution and reduced maximum contact force than fresh ballast. Contact force orientation was also analysed, and it provided more insight into the orientation of contacts transmitted in a granular assembly. 


\section{Acknowledgements}

The Authors acknowledge the financial support provided by Australian Research Council, Cooperative Research Centre for Rail Innovation, and support from the Centre for Geomechanics and Railway Engineering, University of Wollongong, NSW, Australia for the funding of this research. The authors would also like to thank technical staff at the University of Wollongong (Alan Grant, Cameron Neilson and Ian Bridge) for their assistance in the laboratory throughout the period of this study.

\section{Notations}

a coefficient of contact anisotropy

$a_{n} \quad$ coefficient normal force anisotropy

$a_{s} \quad$ coefficient shear force anisotropy

$d$ distance between the particle to particle centre

$e_{f} \quad$ void ratio of fouling material

$e_{b} \quad$ void ratio of fresh ballast

$E(\theta)$ density distribution function of fabric tensor

$\overrightarrow{\boldsymbol{F}}_{N} \quad$ normal force vector

$\overrightarrow{\boldsymbol{F}}_{T} \quad$ shear force vector

$\delta \overrightarrow{\boldsymbol{F}}_{T} \quad$ incremental shear force

$F_{i j} \quad$ fabric tensor

$\bar{f}_{n}(\theta)$ density distribution function of contact normal force tensor

$\bar{f}_{S}(\theta)$ density distribution function of contact shear force tensor

$f_{n}^{k}, f_{s}^{k}$ contact normal force and shear force

$\bar{f}_{0} \quad$ average contact normal force

$G_{s . b} \quad$ specific gravity of ballast

$G_{S . f} \quad$ specific gravity of fouling material 
$k_{n} \quad$ contact normal stiffness

$k_{s} \quad$ contact shear stiffness

$k_{n \text {-wall }}$ contact normal stiffness of wall-particle

$k_{s-w a l l}$ contact shear stiffness of wall-particle

$M_{f} \quad$ dry mass of fouling material

$M_{b} \quad$ dry mass of fresh ballast

$n_{i} \quad$ unit vector

$N_{c} \quad$ total number of contacts

$N_{i j} \quad$ contact normal force tensor

$R^{[A]}, R^{[B]} \quad$ radii of particles $A, B$

$S_{i j} \quad$ contact shear force tensor

$U^{n} \quad$ particle penetration depth

VCI Void Contamination Index

$\mu \quad$ inter-particle friction coefficient

$x_{i}^{[A]}, x_{i}^{[B]} \quad$ particle's centres

$\Delta h \quad$ shear displacement

$\sigma_{n} \quad$ normal stress

$\sigma_{2,3} \quad$ lateral confining stresses

$\theta_{a} \quad$ major principal directions of contact anisotropy

$\theta_{n} \quad$ major principal directions of contact normal force anisotropy

$\theta_{s}$ major principal directions of contact shear force anisotropies 


\section{References}

Australian Standard: AS2758.7 (1996). Aggregates and rock for engineering purposes; Part 7: Railway ballast. Sydney, NSW, Australia.

Bathurst, R. J. , and Raymond, G. P. (1987). "Geogrid reinforcement of ballasted track".

Transportation Research Record. 1153: 8-14.

Biabani, M. M., Indraratna, B., and Ngo, N. T. (2016a). "Modelling of geocell-reinforced subballast subjected to cyclic loading". Geotextiles and Geomembranes. 44(4), pp: 489-503.

Biabani, M. M., Ngo, N. T., and Indraratna, B. (2016b). "Performance evaluation of railway subballast stabilised with geocell based on pull-out testing". Geotextiles and

Geomembranes.44(4): 579-591.

Brown, S. F., Kwan, J. , and Thom, N. H. (2007). "Identifying the key parameters that influence geogrid reinforcement of railway ballast". Geotextiles and Geomembranes. 25(6): 326-335.

Brown, S. F., Thom, N. H. , and Kwan, J. (2006). "Optimising the geogrid reinforcement of rail track ballast". Railfound Conference, Birmingham.

Budiono, D. S., McSweeney, T., Dhanasekar, M., and Gurung, N. (2004). "The effect of coal dust fouling on the cyclic behaviour of railtrack ballast". Cyclic Behaviour of Soils and Liquefaction phenomena, Taylor \& Francis Group, London.

Charles, J. A. and Watts, K. S. (1980). "The influence of confining pressure on the shear strength of compacted rockfill." Geotechnique, 30(4): 353-367.

Chen, C., McDowell, G. R., and Thom, N. H. (2012). "Discrete element modelling of cyclic loads of geogrid-reinforced ballast under confined and unconfined conditions". Geotextiles and Geomembranes. 35(0): 76-86.

Cundall, P. A., and Strack, O. D. L. (1979). "A discrete numerical model for granular assemblies". Geotechnique. 29(1): 47-65.

Feldman, F. , and Nissen, D. (2002). "Alternative testing method for the measurement of ballast fouling". Conference on Railway Engineering, Wollongong, RTSA.

Ferellec, J. F. , and McDowell, G. R. (2010). "Modelling realistic shape and particle inertia in DEM". Geotechnique. 60(3): 227-232.

Fernandes, G., Palmeira, E. M. , and Gomes, R. C. (2008). "Performance of geosyntheticreinforced alternative sub-ballast material in a railway track". Geosynthetics International. 15(5): 311-321. 
Fortunato, E., Pinelo, A. , and Fernandes, M. (2010). "Characterization of the fouled ballast layer in the substructure of a 19th century railway track under renewal". Soils and Foundations. 50(1): $55-62$.

Huang, H. , and Tutumluer, E. (2011). "Discrete element modeling for fouled railroad ballast". Construction and Building Materials. 25: 3306-3312.

Indraratna, B., Nimbalkar, S. , and Tennakoon, N. (2010a). "The behaviour of ballasted track foundations: Track drainage and geosynthetic reinforcement". GeoFlorida 2010: Advances in Analysis, Modeling \& Design (GSP 199). Fratta, D., Puppala, A. and Muhunthan, B. (Eds.) 23782387.

Indraratna, B., Thakur, P. K., and Vinod, J. S. (2010b). "Experimental and numerical study of railway ballast behaviour under cyclic loading". International Journal of Geomechanics, ASCE. 10(4): 136-144.

Indraratna, B., Salim, W. , and Rujikiatkamjorn, C. (2011a). Advanced rail geotechnology ballasted track, CRC Press, Taylor \& Francis Group, London, UK

Indraratna, B., Ngo, N. T. , and Rujikiatkamjorn, C. (2011b). "Behavior of geogrid-reinforced ballast under various levels of fouling". Geotextiles and Geomembranes. 29(3): 313-322.

Indraratna, B., Ngo, N. , and Rujikiatkamjorn, C. (2013). "Deformation of coal fouled ballast stabilized with geogrid under cyclic load". Journal of Geotechnical and Geoenvironmental Engineering. 139(8): 1275-1289.

Indraratna, B., Ngo, N., Rujikiatkamjorn, C. , and Vinod, J. (2014). "Behavior of fresh and fouled railway ballast subjected to direct shear testing: Discrete element simulation". International Journal of Geomechanics. 14(1): 34-44.

ITASCA. (2012). Particle Flow Code in three dimensions. Itasca Consulting Group, Inc., Minnesota.

Kwon, J. , and Penman, J. (2009). "The use of biaxial geogrids for enhancing the performance of sub-ballast and ballast layers-previous experience and research". Bearing Capacity of Road, Railways and Airfields

Lackenby, J., Indraratna, B., McDowell, G. R. , and Christie, D. (2007). "Effect of confining pressure on ballast degradation and deformation under cyclic triaxial loading". Géotechnique. 57(6): 527-536.

Lim, W. L. , and McDowell, G. R. (2005). "Discrete element modelling of railway ballast". Granular Matter. 7(1): 19-29.

Lobo-Guerrero, S. , and Vallejo, L. E. (2006). "Discrete element method analysis of railtrack ballast degradation during cyclic loading". Granular Matter. 8(3-4): 195-204. 
Lu, M. , and McDowell, G. R. (2008). "Discrete element modelling of railway ballast under triaxial conditions". Geomechanics and Geoengineering: An International Journal. 3(4): 257-270.

Marsal, R. J. (1973). Mechanical Properties of Rockfill. In: Embankment dam engineering. Wiley, New York, pp. 109-200.

McDowell, G. R., Harireche, O., Konietzky, H., Brown, S. F. , and Thom, N. H. (2006). "Discrete element modelling of geogrid-reinforced aggregates". Proceedings of the ICE - Geotechnical Engineering 159(1): 35-48.

McDowell, G. R. , and Stickley, P. (2006). "Performance of geogrid-reinforced ballast". Ground Engineering. 1(1): 26-33.

Ngo, N. T., Indraratna, B. , and Rujikiatkamjorn, C. (2014). "DEM simulation of the behaviour of geogrid stabilised ballast fouled with coal". Computers and Geotechnics, 55(2014): 224-231.

Ngo, N.T., Indraratna, B., Rujikiatkamjorn, C. and Mahdi Biabani, M. (2015). "Experimental and discrete element modeling of geocell-stabilized subballast subjected to cyclic loading". Journal of Geotechnical and Geoenvironmental Engineering, 142(4): p.04015100

Oda, M. , and Iwashita, K. (1999). Mechanics of granular materials: An introduction, Rotterdam: A. A. Balkema.

Raymond, G. P. (2002). "Reinforced ballast behaviour subjected to repeated load". Geotextiles and Geomembranes. 20(1): 39-61.

Rothenburg, L. (1980). Micromechanics of idealized granular systems. PhD dissertation, Carleton University, Ottawa, Canada.

Rothenburg, L. , and Bathurst, R. J. (1989). "Analytical study of induced anisotropy in idealized granular materials". Geotechnique. 39(4): 601-614.

Selig, E. T. , and Waters, J. M. (1994). Track geotechnology and substructure management, Thomas Telford, London.

Thakur, P. K., Vinod, J. S. , and Indraratna, B. (2010). "Effect of particle breakage on cyclic densification of ballast: A DEM approach". Materials Science and Engineering. 10: 1-7.

Tutumluer, E., Dombrow, W. , and Huang, H. (2008). "Laboratory characterization of coal dust fouled ballast behaviour". AREMA 2008 Annual Conference \& Exposition, Salt Lake City, UT, USA.

Tutumluer, E., Huang, H. , and Bian, X. (2011). "Geogrid-aggregate interlock mechanism investigated through aggregate imaging based discrete element modeling approach". International Journal of Geomechanics, ASCE. 


\section{List of Table}

Table 1.Micromechanics parameters of geogrid, ballast, and coal fines adopted for DEM simulations

\begin{tabular}{|l|l|l|l|}
\hline Parameter & Geogrid & Ballast & Coal fines \\
\hline Particle density $\left(\mathrm{kg} / \mathrm{m}^{3)}\right.$ & 750 & 2700 & 800 \\
Coefficient of friction & 0.5 & 0.8 & 0.2 \\
Contact normal stiffness, $k_{n}(\mathrm{~N} / \mathrm{m})$ & $1.77 \times 10^{7}$ & $0.52 \times 10^{8}$ & $1.27 \times 10^{4}$ \\
Contact shear stiffness, $k_{s}(\mathrm{~N} / \mathrm{m})$ & $0.88 \times 10^{7}$ & $0.52 \times 10^{8}$ & $1.27 \times 10^{4}$ \\
Contact normal stiffness of wall-particle, $\mathrm{k}_{\mathrm{n}-\mathrm{wall}}(\mathrm{N} / \mathrm{m})$ & $1 \times 10^{8}$ & $1 \times 10^{8}$ & $1 \times 10^{8}$ \\
Shear stiffness of wall of wall-particle, $\mathrm{k}_{\mathrm{s}-\mathrm{wall}}(\mathrm{N} / \mathrm{m})$ & $1 \times 10^{8}$ & $1 \times 10^{8}$ & $1 \times 10^{8}$ \\
Parallel bond radius multiplier, $r_{p}$ & 0.5 & & \\
Parallel bond normal stiffness, $k_{n p}(\mathrm{kPa} / \mathrm{m})$ & $5.68 \times 10^{8}$ & & \\
Parallel bond shear stiffness, $k_{s p}(\mathrm{kPa} / \mathrm{m})$ & $5.68 \times 10^{8}$ & & \\
Parallel bond normal strength, $\sigma_{n p}(\mathrm{MPa})$ & 456 & 456 & \\
Parallel bond shear strength, $\sigma_{s p}(\mathrm{MPa})$ & & & \\
\hline
\end{tabular}




\section{List of figures}

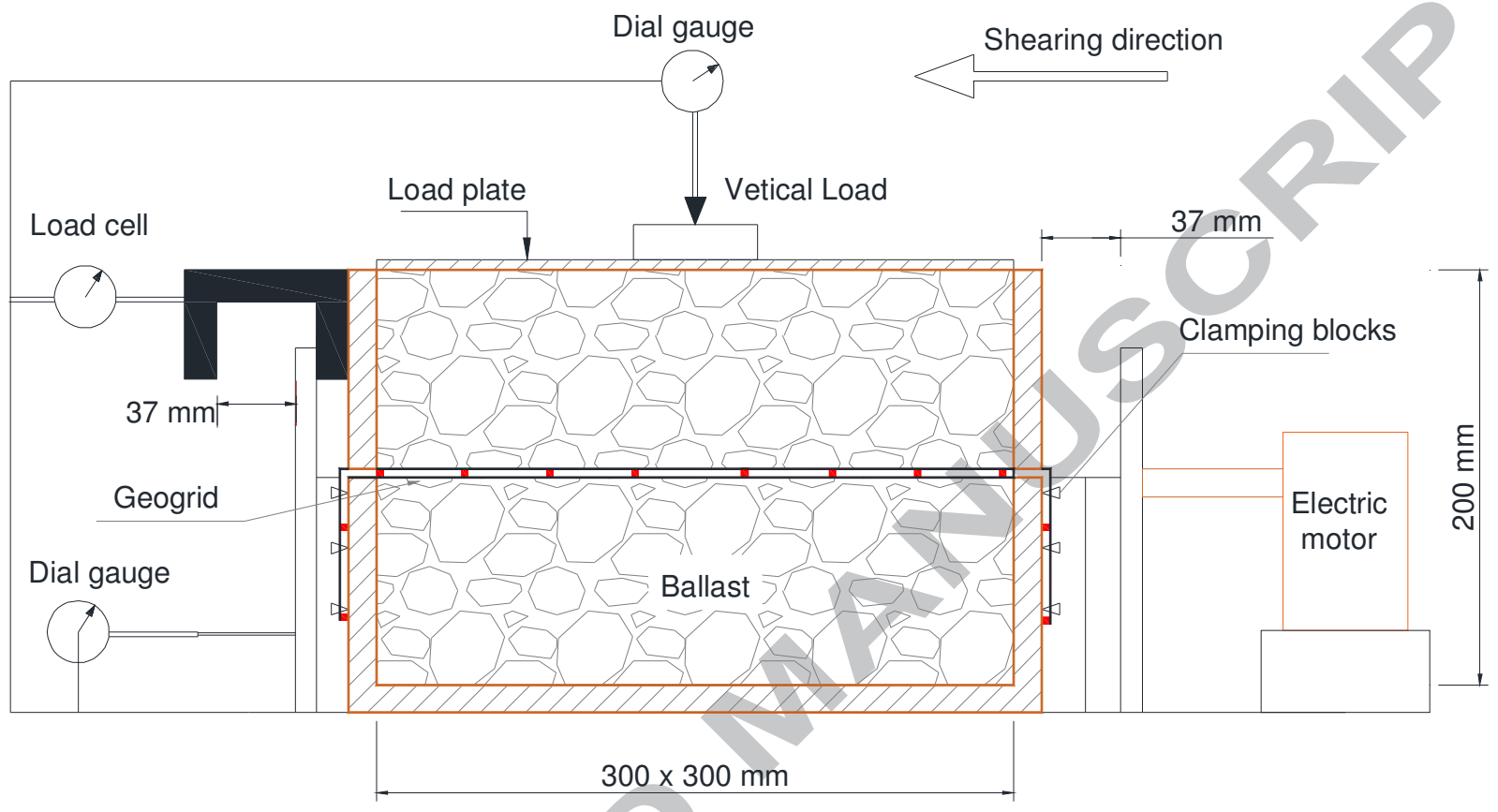

Figure 1. Schematic diagram of the large-scale direct shear test set up 


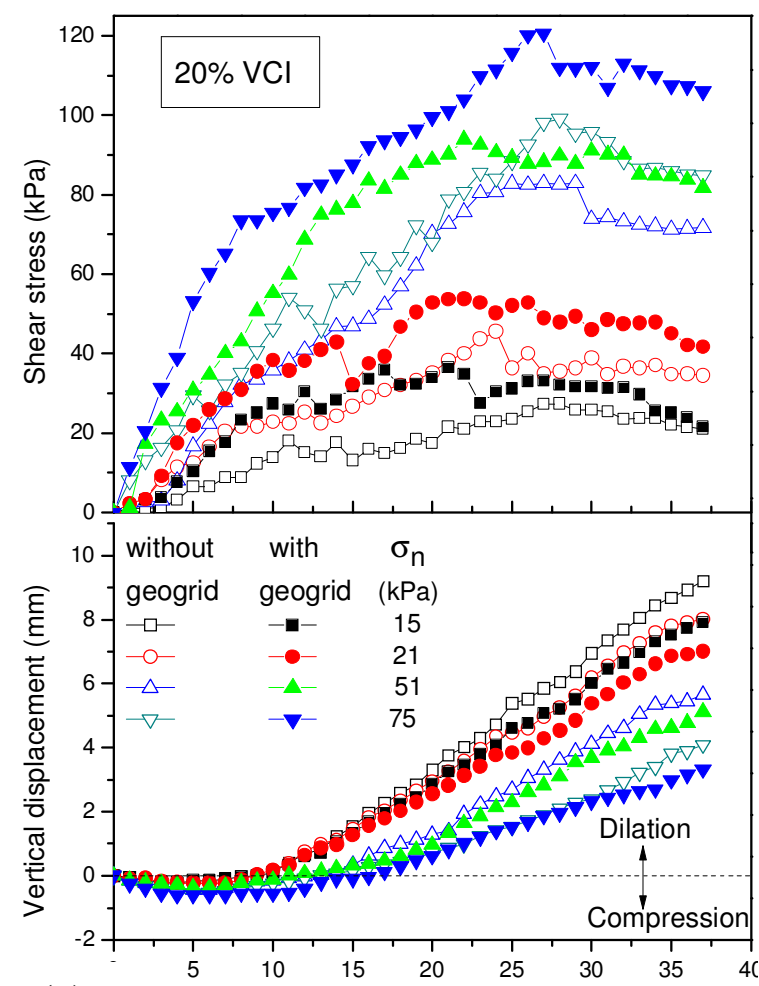

(a)

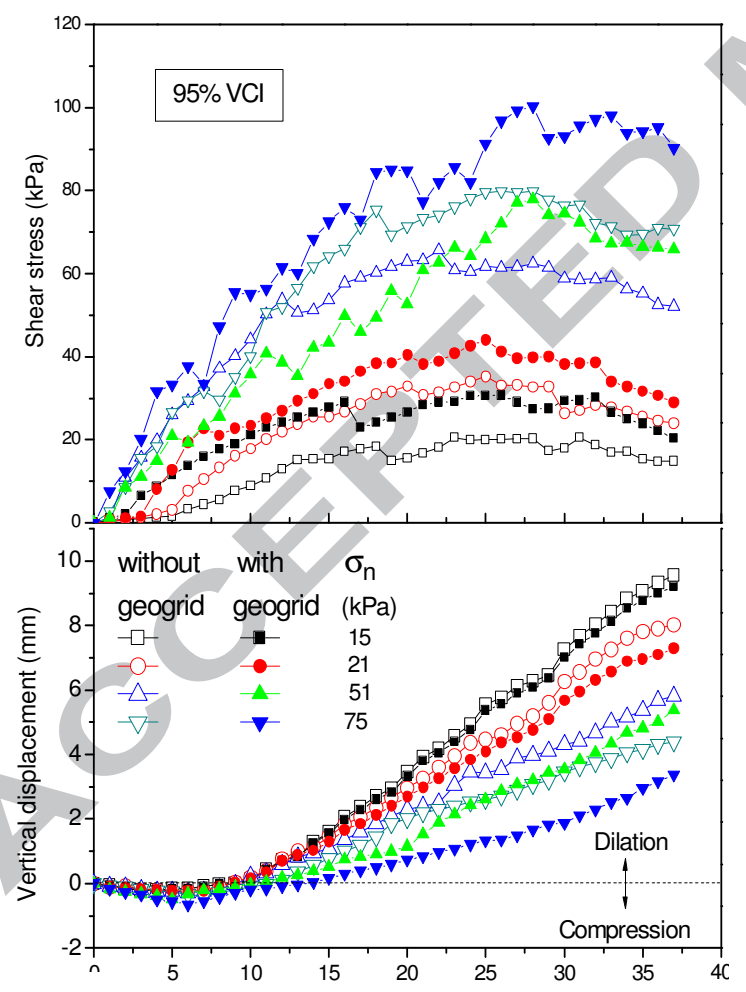

(c)

Horizontal displacement (mm)

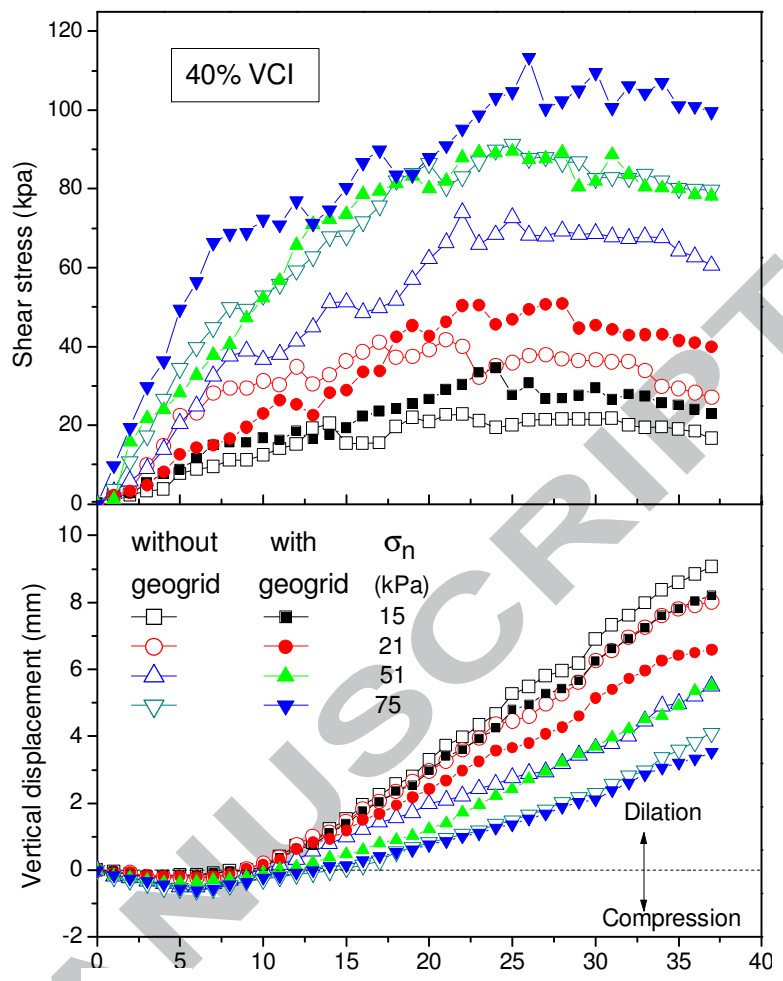

(b)

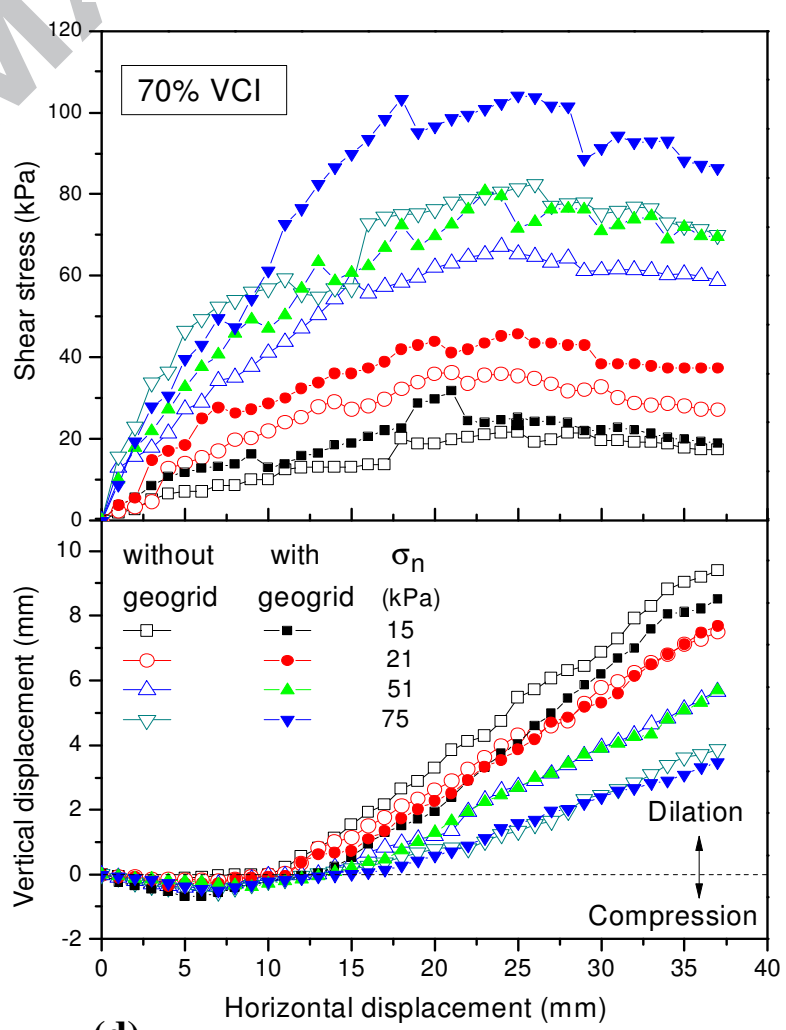

(d)

Figure 2. Shear stress-displacement behaviour of fouled ballast: (a) VCI=20\%. (b) VCI=40\%, (c) $\mathrm{VCI}=70 \%$ and (d) $\mathrm{VCI}=95 \%$ (modified after Indraratna et al. $2011 \mathrm{~b}$ ) 


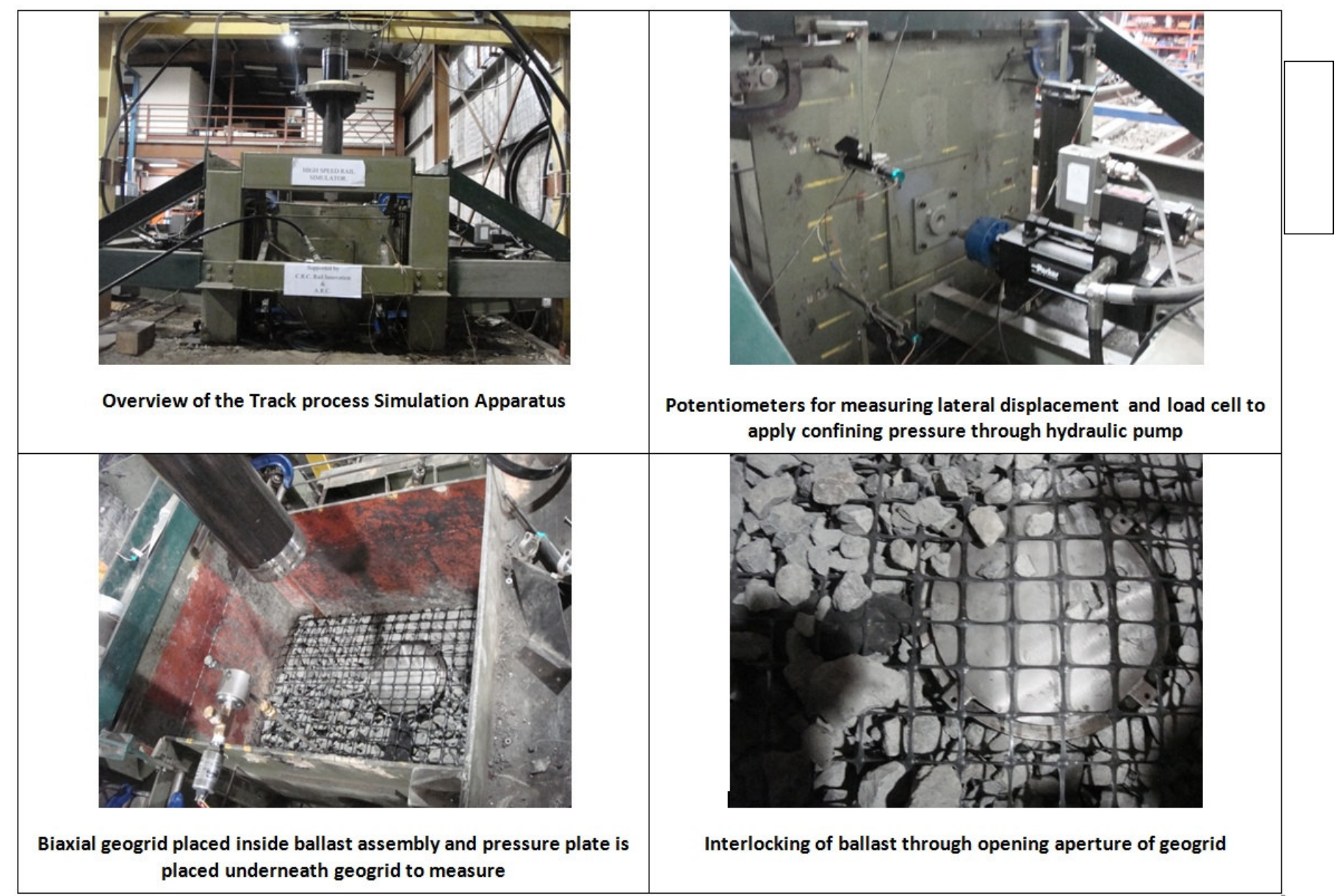

Figure 3. Overview of the TPSA apparatus and its main components used in cyclic tests 


\section{ACCEPTED MANUSCRIPT}
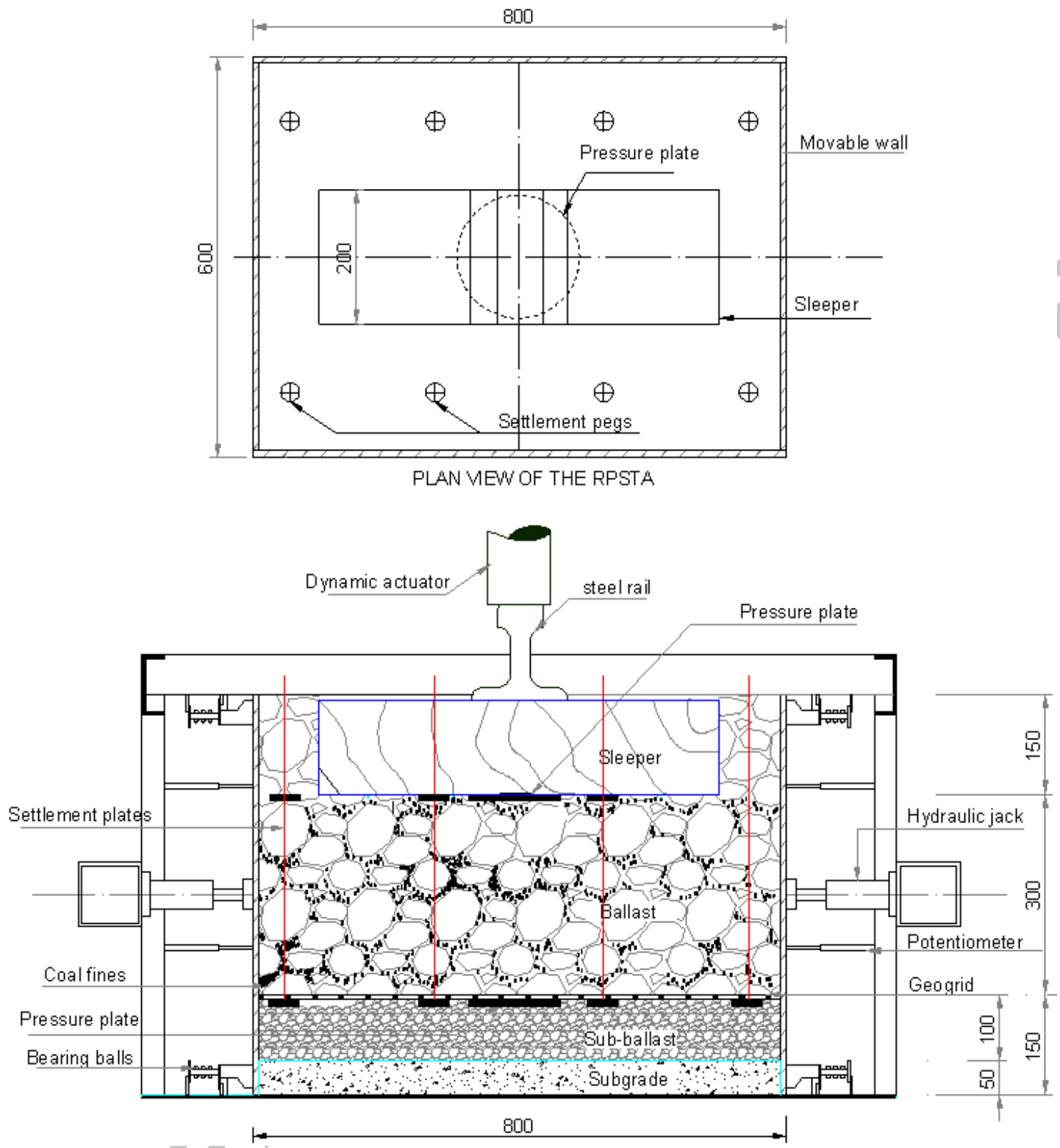

Figure 4. Schematic plane view and cross-section of the TPSA (unit: $\mathrm{mm}$ ) 


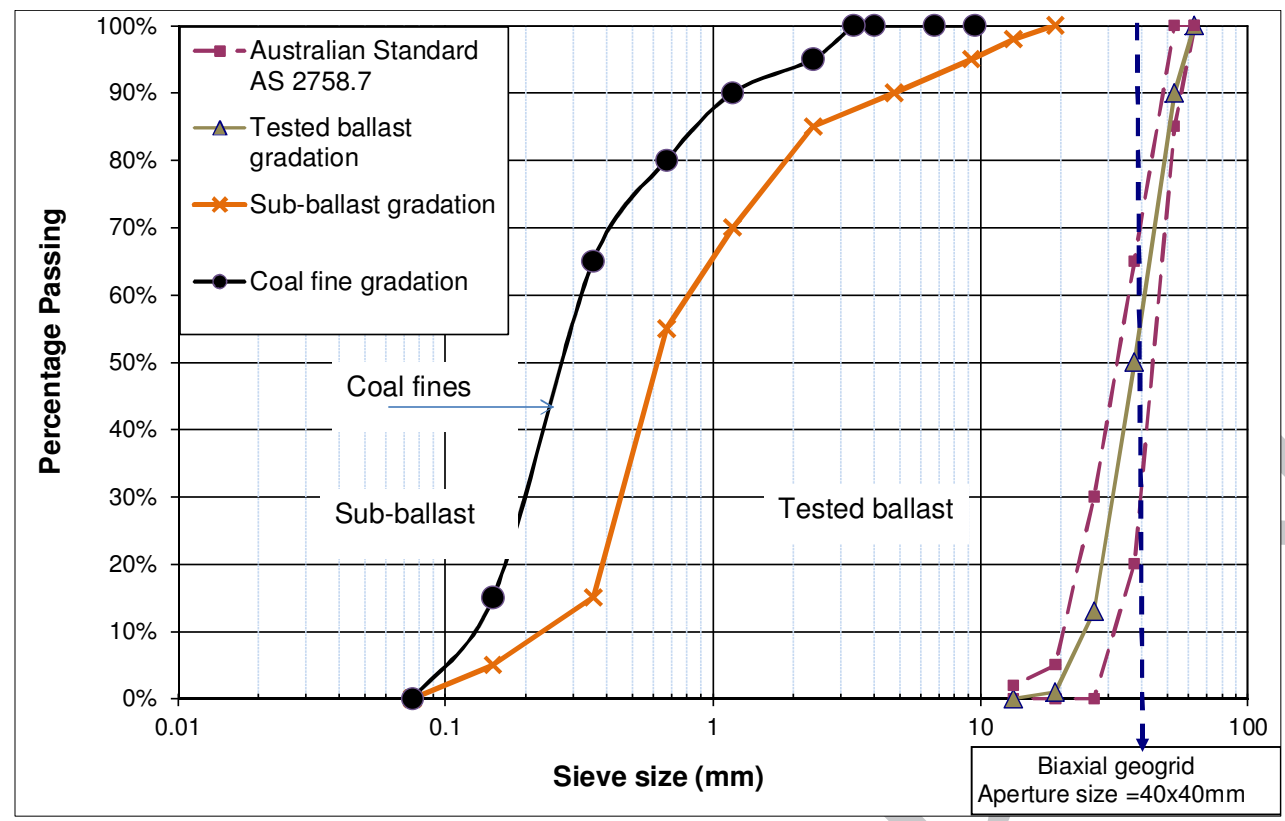

Figure 5. Particle size distribution of ballast, sub-ballast and coal fines used in the tests 


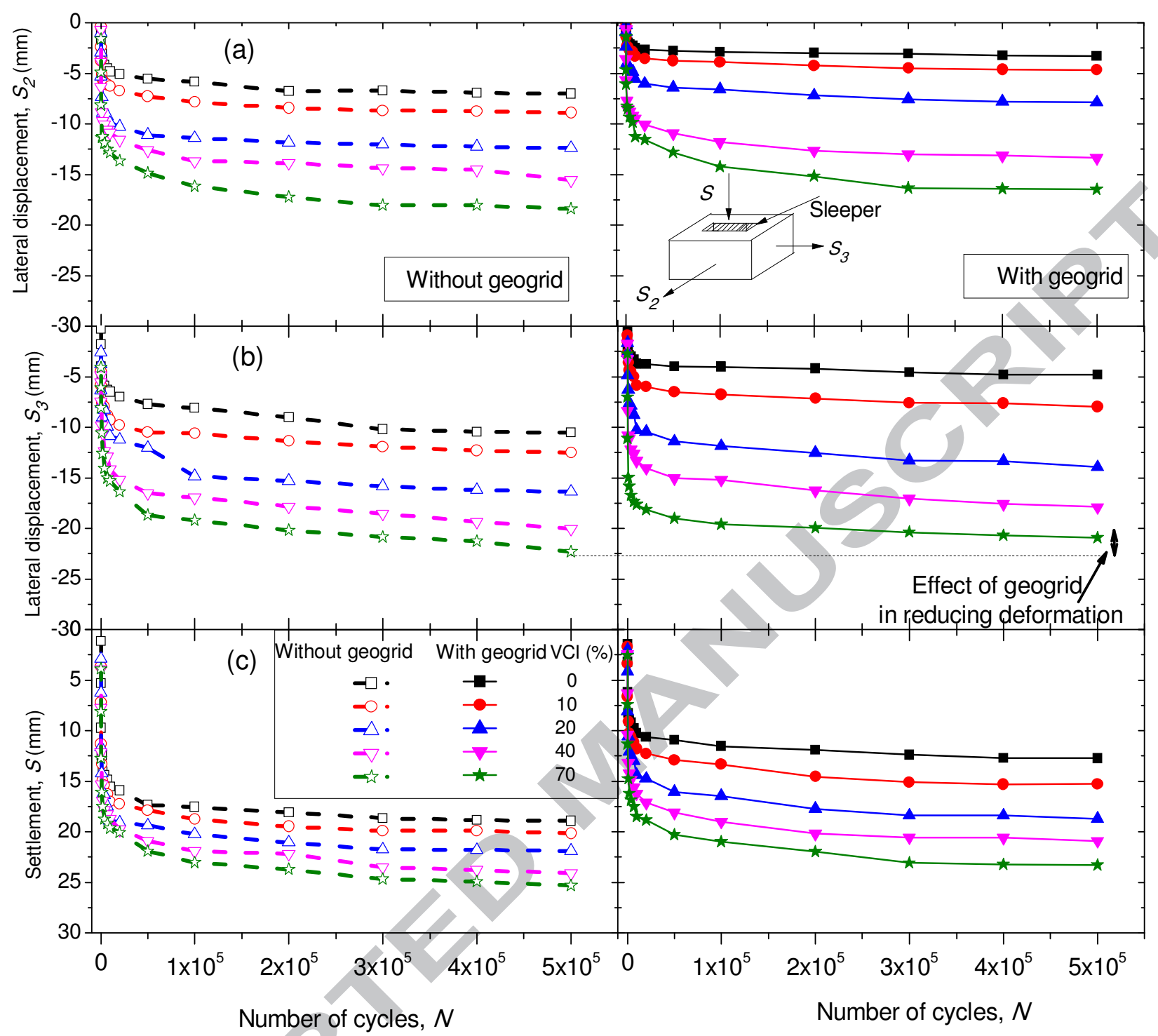

Figure 6. Deformation of coal-fouled ballast at varying VCIs: (a) lateral displacement (perpendicular to sleeper); (b) lateral displacement (parallel to sleeper); (c) vertical settlement (modified after Indraratna el al. 2013) 


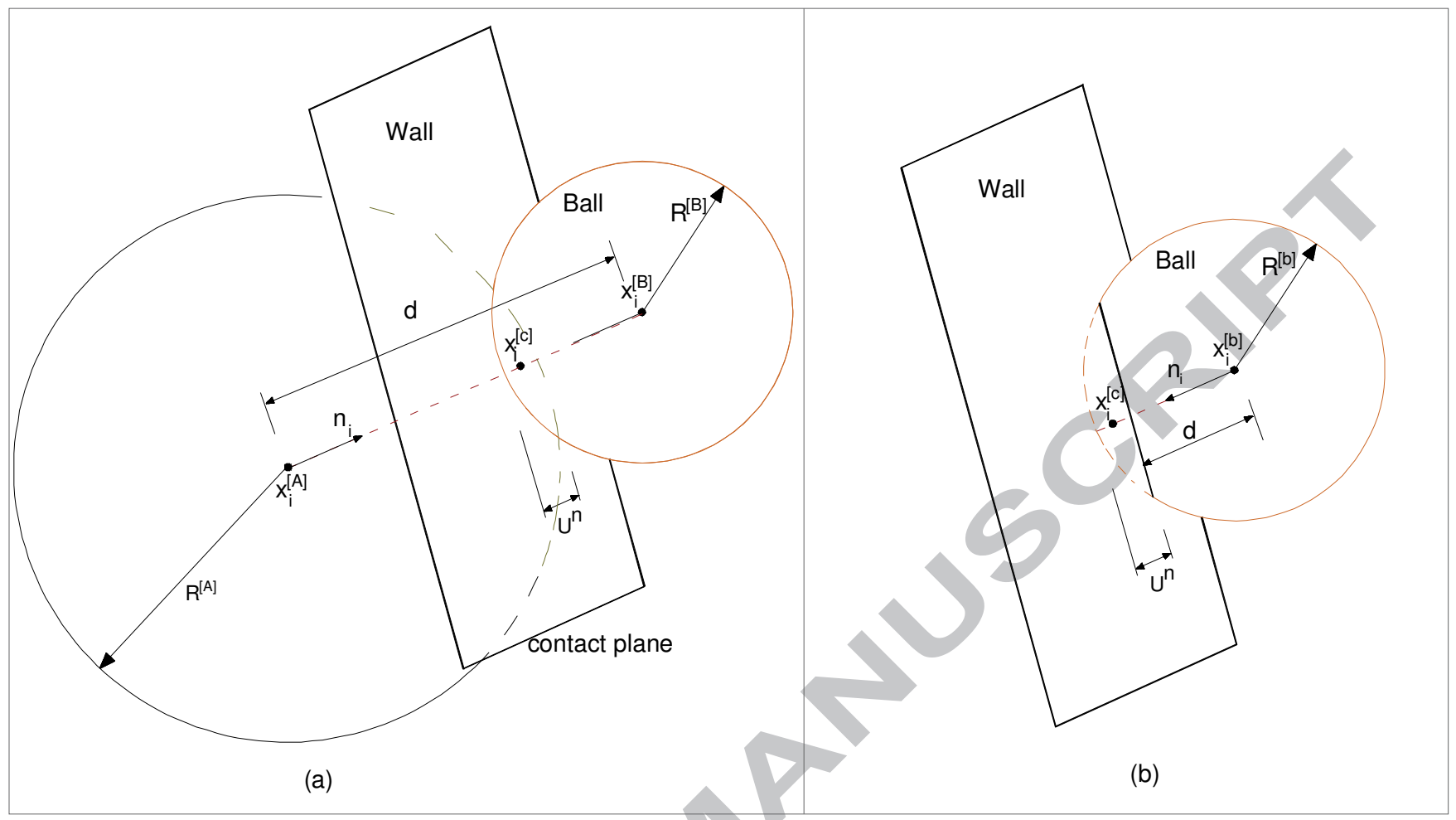

Figure 7. Notation used to describe contacts in DEM: (a) ball-ball contact; (b) ball-wall contact 


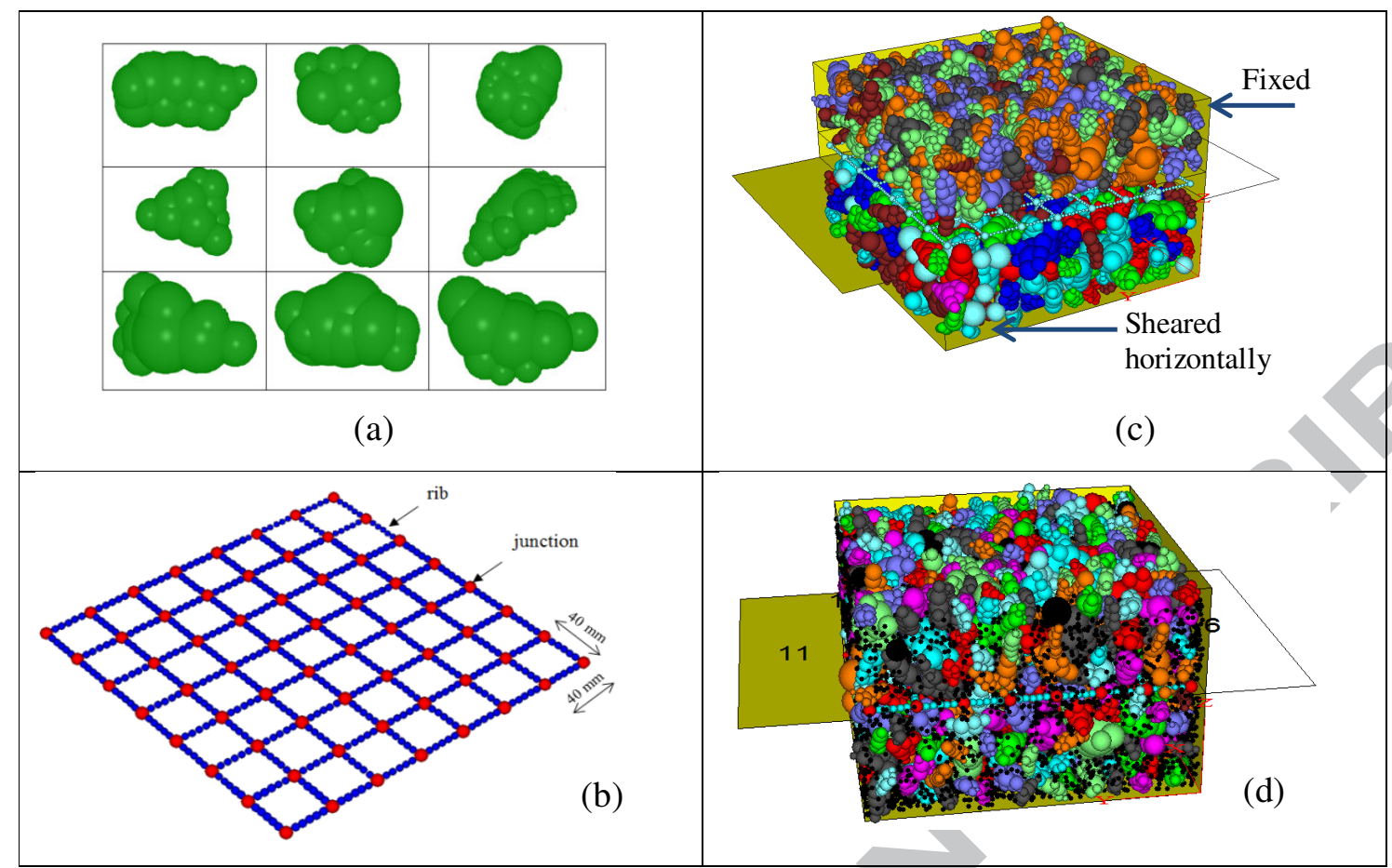

Figure 8. DEM simulation for direct shear test: (a) simulated particles; (b) simulated geogrid; (c) direct shear test for fresh ballast; (d) direct shear test for 40\%VCI-fouled ballast (modified after Ngo et al. 2014) 

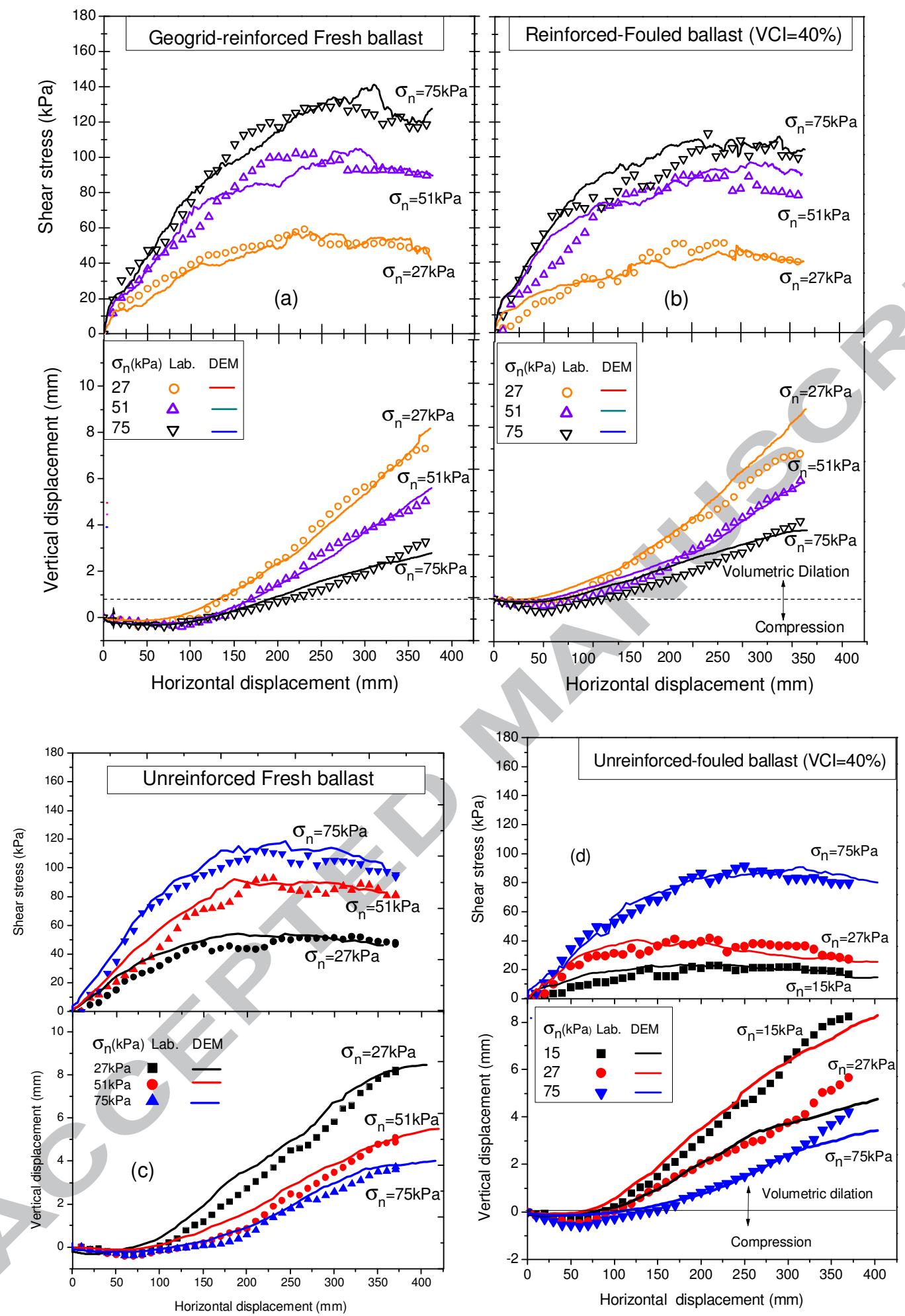

Figure 9. Comparisons of shear stress and vertical displacement versus shear displacement between experimental data and DEM simulation: (a) and (b) Geogrid-reinforced fresh and fouled ballast; (c) and (d) Unreinforced-fresh and fouled ballast (modified after Ngo et al. 2014) 

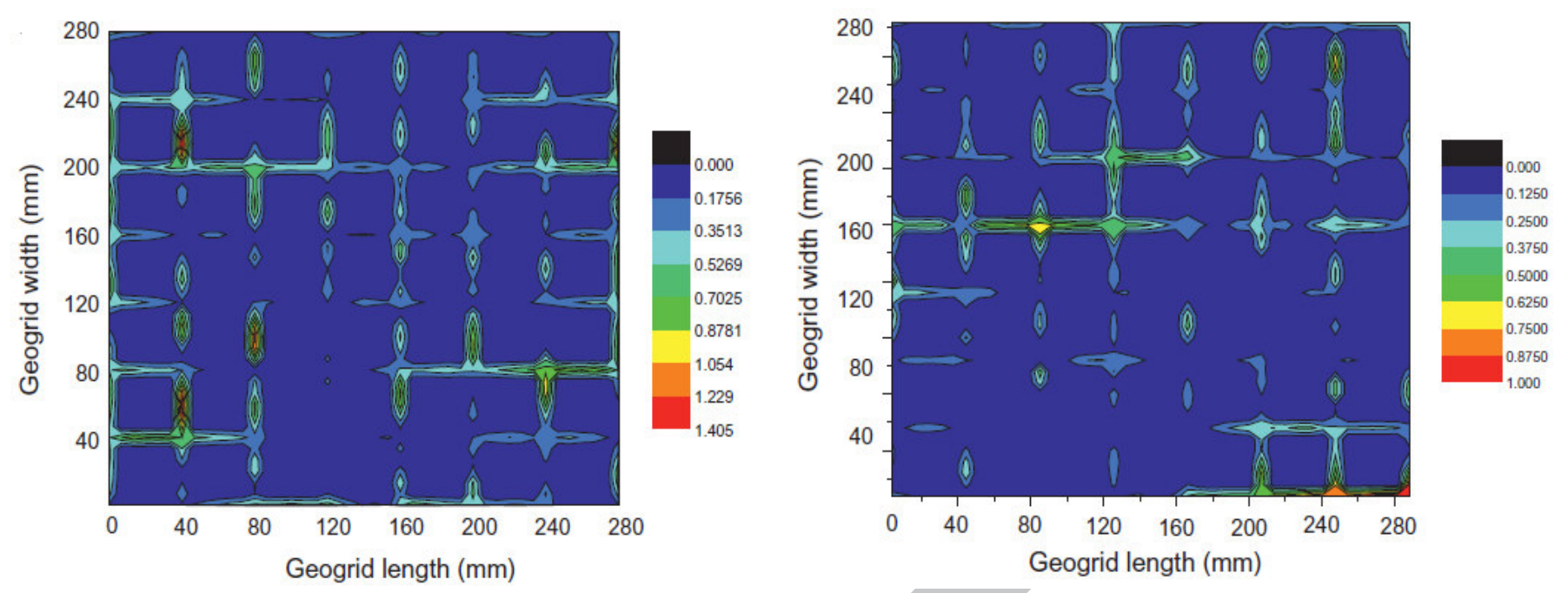

Figure 10. Contour strain in horizontal shearing direction developed across the geogrid at the end of test: (a) fresh ballast and (b) 40\% VCI fouled ballast (modified after Ngo et al. 2014) 


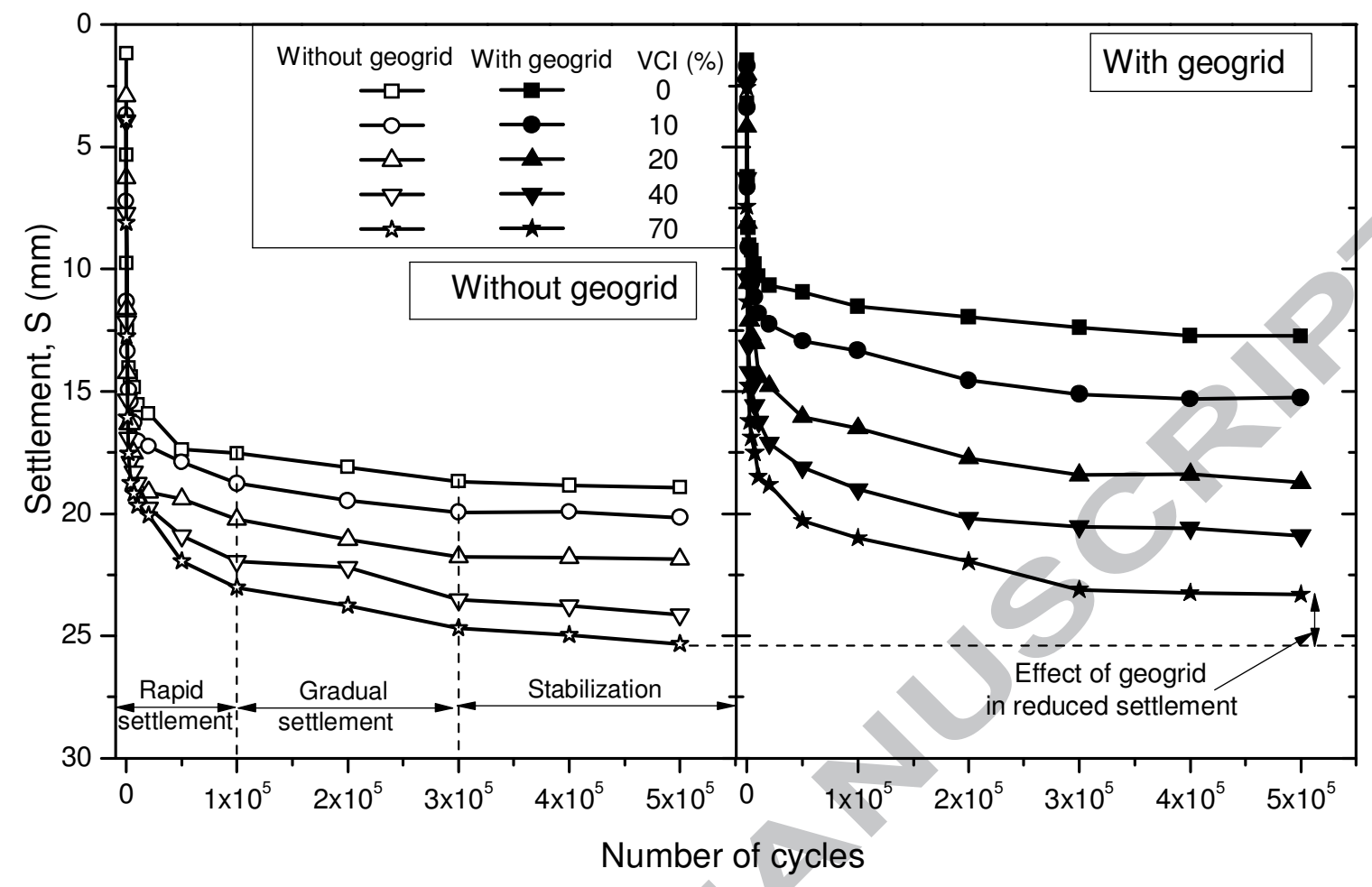

Figure 11. Variations of the vertical settlement, $S$ of fresh and fouled ballast with and without geogrid inclusion with varying $V C I s$ 

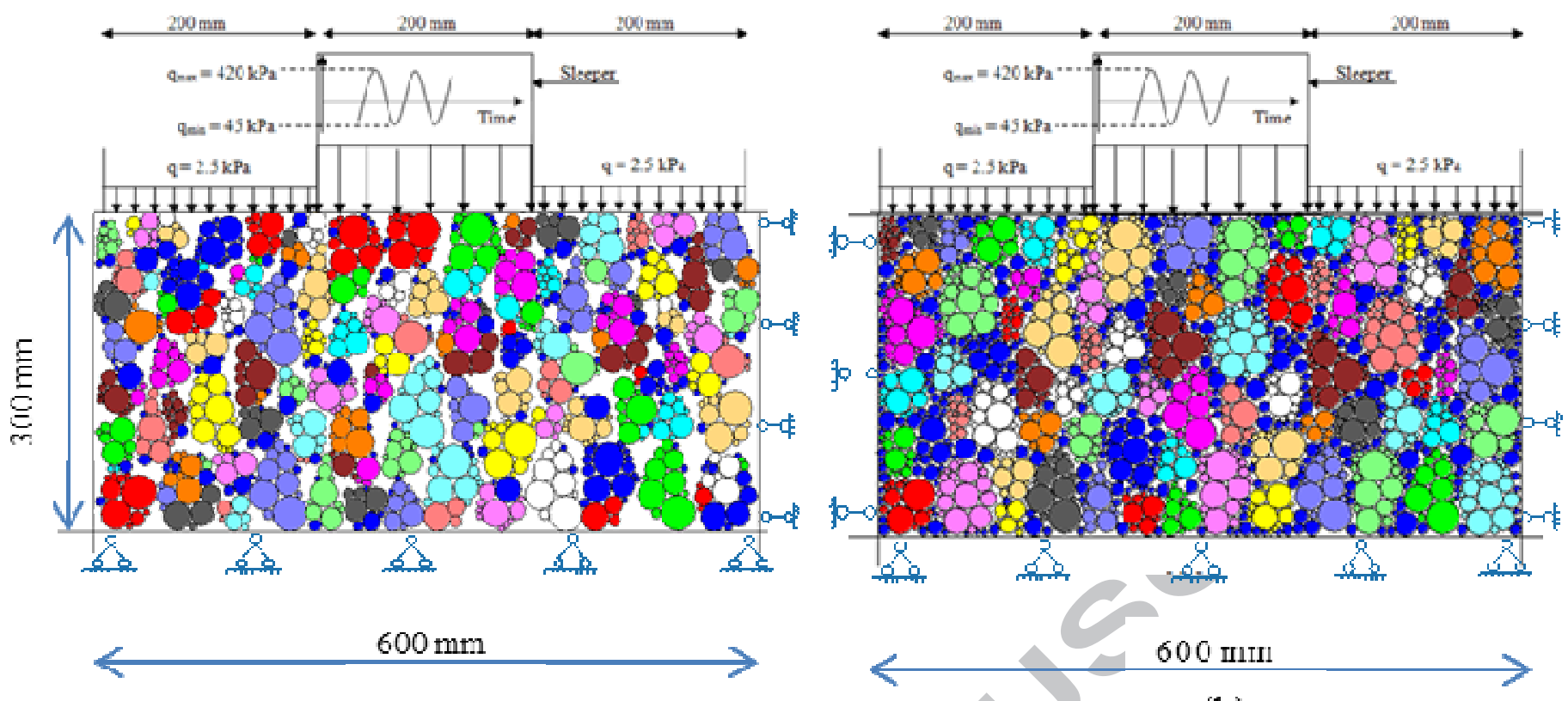

(b)

Figure 12. DEM simulation for cyclic tests: (a) fresh ballast; (b) fouled ballast (VCI=70\%) 


\section{ACCEPTED MANUSCRIPT}

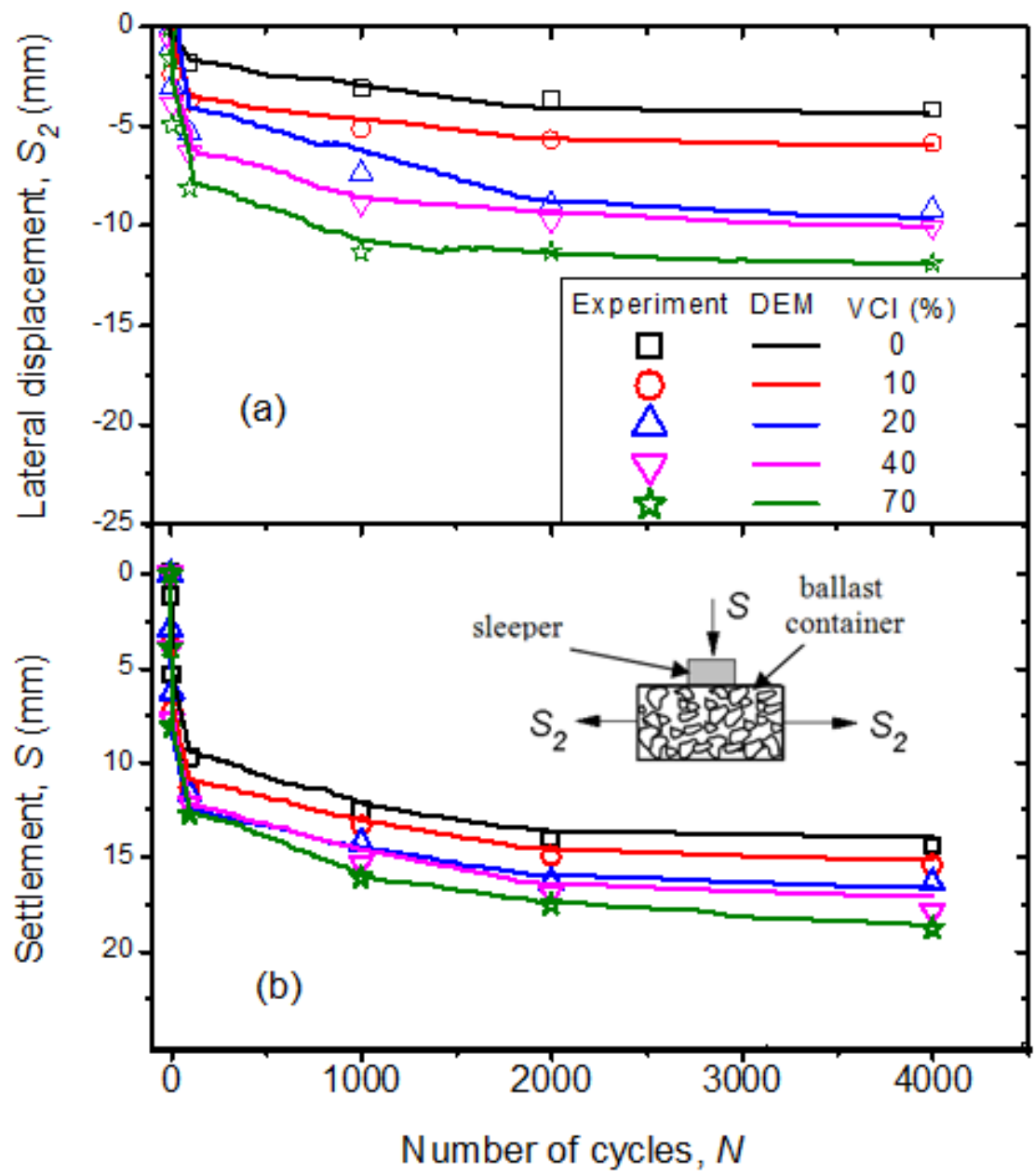

Figure 13. Comparisons of lateral displacement, settlement with load cycles obtained from DEM simulations and data measured in the laboratory 


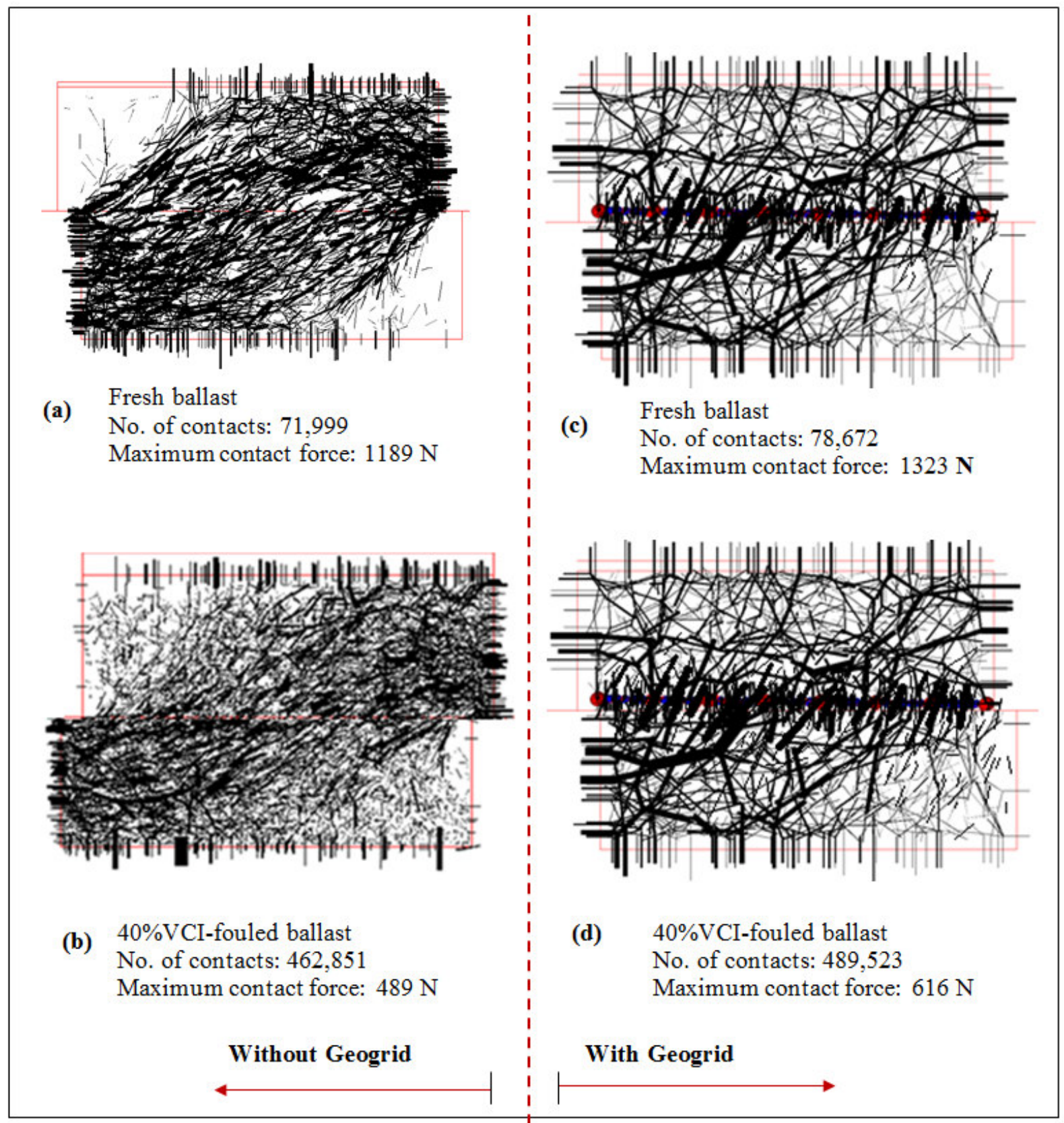

Figure 14. Distributions of contact forces: (a) unreinforced-fresh ballast; (b) 40\%VCI-unreinfoced ballast; (c) geogrid-reinforced fresh ballast; (d) 40\%VCI-geogrid reinforced ballast (modified after Ngo et al. 2014) 


\section{Contact orientation}

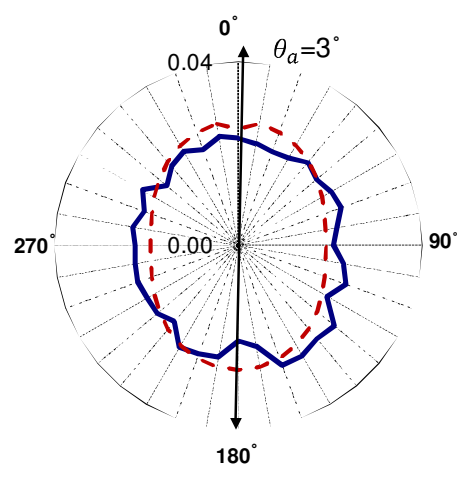

Normal force orientation

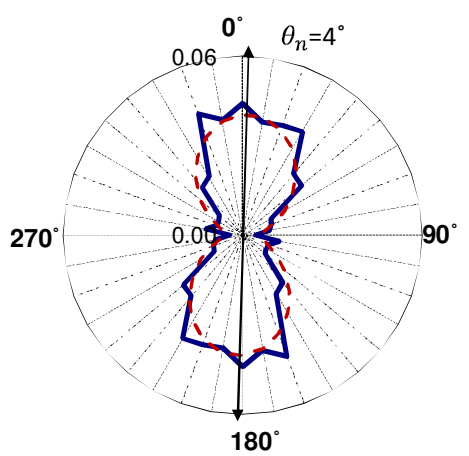

Shear force orientation

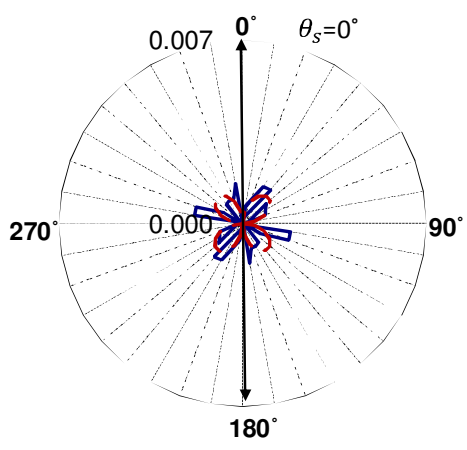

(a) Shear displacement $\Delta h=0 \mathrm{~mm}$
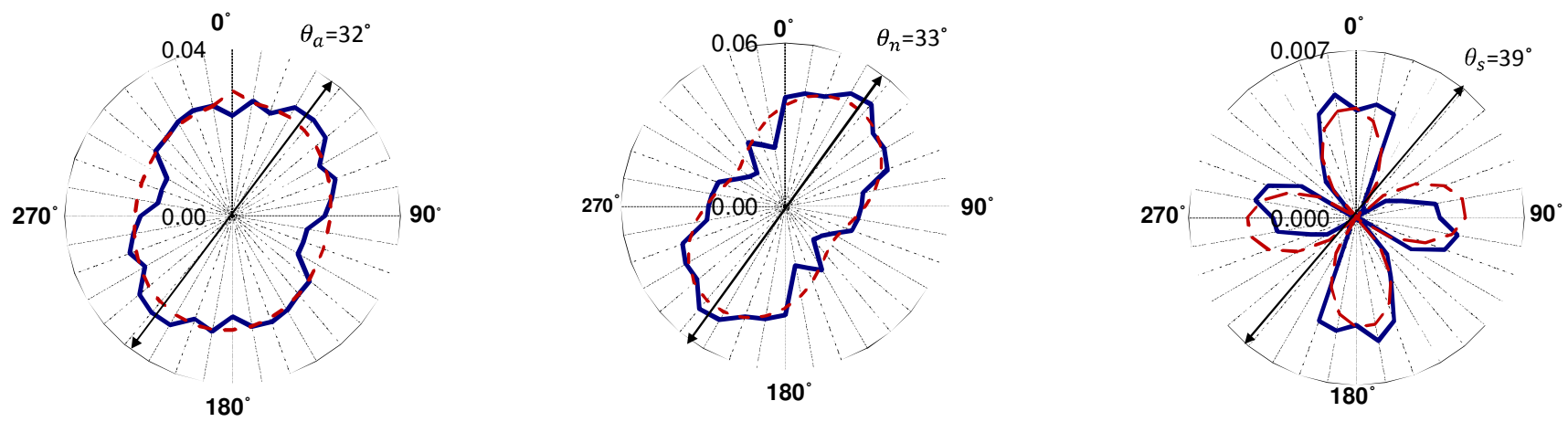

(b) Shear displacement $\Delta h=9 \mathrm{~mm}$
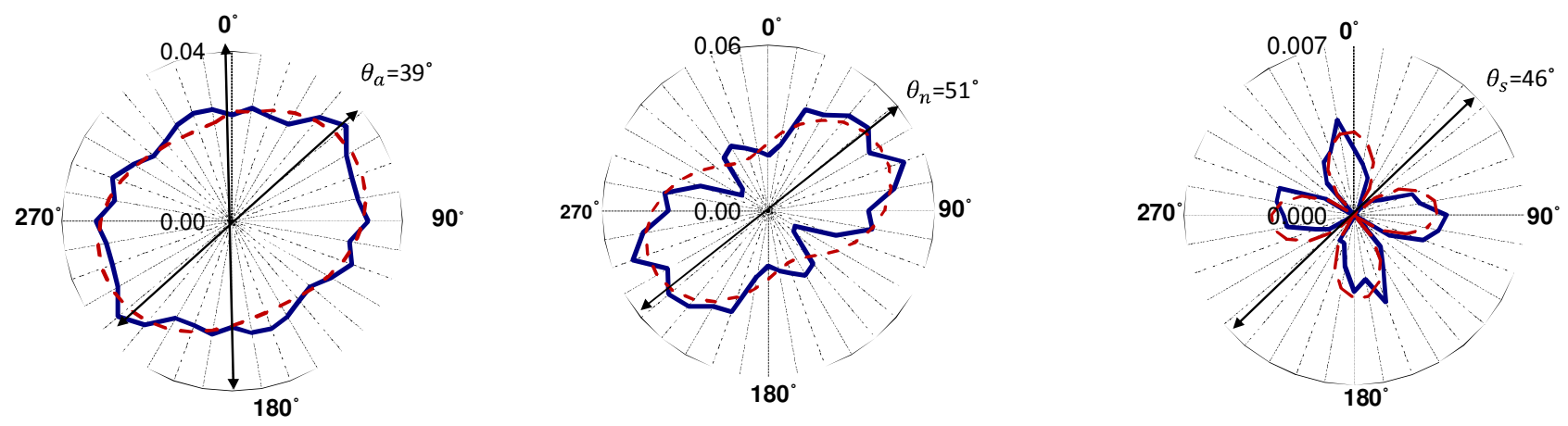

(c) Shear displacement $\Delta h=18 \mathrm{~mm}$

- Simulation data

- -Fourier series approximation

Figure 15. Polar histograms of contact and force orientations in the fouled ballast assembly (VCI=40\%) at varying shear displacement $\Delta h$ :(a) $\Delta h=0 \mathrm{~mm}$; (b) $\Delta h=9 \mathrm{~mm}$; and (c) $\Delta h=18 \mathrm{~mm}$ 


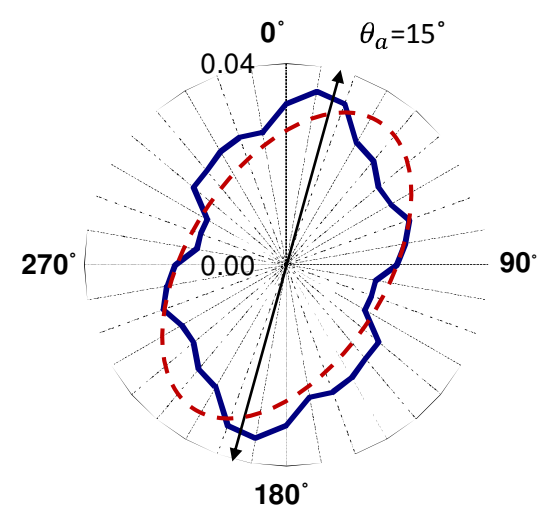

(a)

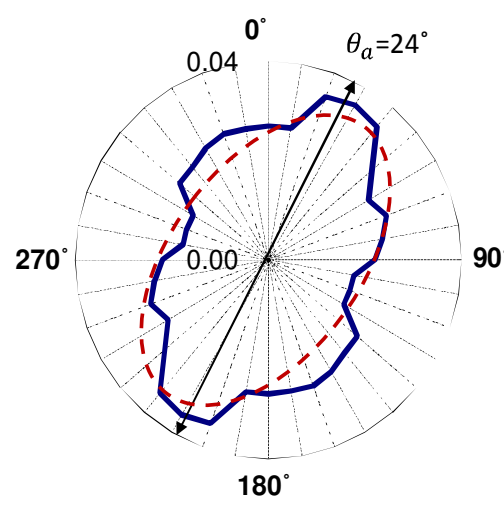

(b)

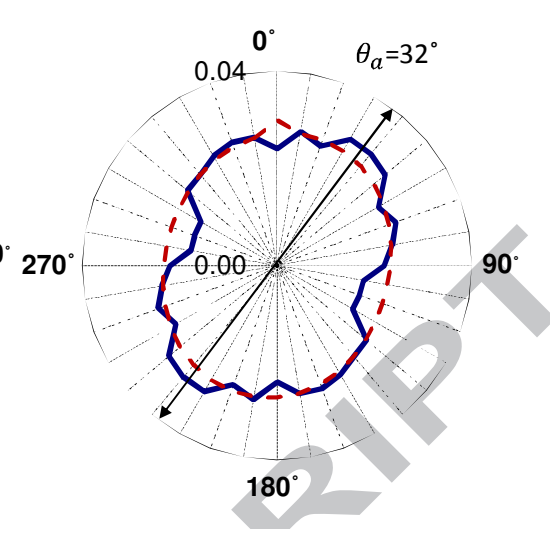

(c)

Figure 16. Polar histograms of contact orientations at a shear displacement of $\Delta h=9 \mathrm{~mm}$ : (a) geogridreinforced-fresh ballast; (b) unreinforced-fresh ballast; and (c) unreinforced-fouled ballast (VCI=40\%) 